\title{
Transient Analysis of Isothermal Elastohydrodynamic Point Contacts under Complex Kinematics of Combined Rolling, Spinning and Normal Approach
}

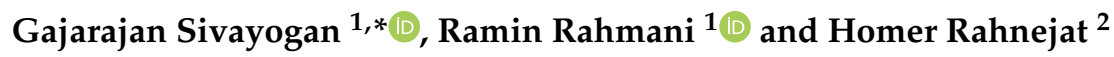 \\ 1 Wolfson School of Mechanical, Electrical and Manufacturing Engineering, Loughborough University, \\ Leicestershire LE11 3TU, UK; r.rahmani@lboro.ac.uk \\ 2 School of Engineering, University of Central Lancashire, Preston PR 1 2HE, UK; HRahnejat@uclan.ac.uk \\ * Correspondence: G.Sivayogan@lboro.ac.uk
}

Received: 3 July 2020; Accepted: 3 August 2020; Published: 5 August 2020

\begin{abstract}
This paper presents a brief review of elastohydrodynamic analysis in commemoration of the immense contributions of Duncan Dowson. This paper also presents an elastohydrodynamic analysis of the elliptical point contact problem under steady state as well as transient conditions. The overall methodology is validated against numerical predictions and experimental observations of acknowledged historical sources. The validated methodology is used to make original contributions in the elastohydrodynamics of elliptical point contact subjected to complex combined contact kinematics, including rolling/sliding, mutual convergence and separation (squeeze film motion) of contacting pairs, when subjected to reciprocating and spinning motions. This combined complex contact kinematics under transient conditions has not hitherto been reported in the literature. This paper shows the critical role of squeeze film motion upon lubricant film thickness. The results also show that the influence of spin motion is only significant at fairly high values of angular velocity and in the absence of a rolling/sliding motion.
\end{abstract}

Keywords: elastohydrodynamic lubrication; elliptical point contacts; transient analysis; complex combined contact kinematics

\section{Introduction}

Highly loaded counterformal lubricated contacts are often subjected to elastohydroynamic regime of lubrication (EHL). In fact, $90 \%$ of all machines and mechanisms comprise load bearing and power transmitting contacts operating under EHL. There has been a plethora of elastohydrodynamic analysis of machine elements such as ball bearings with ball-race elliptical point contact elastohydrodynamics [1-8]. Cylindrical and tapered rolling element bearings operate in finite line contact EHL [9-14], a condition which also extends to the case of involute spur gears [15-20] and helical teeth pair contacts [21-23]. On the other hand, elliptical point contact EHL occurs in bevel and hypoid gear teeth pairs [24-30]. Aside from these counterforming gear teeth pairs, other, even closely conforming teeth pairs, are also subject to EHL under highly loaded conditions such as circular arc or Novikov gears, where a lubricant entraining motion into the contact occurs along the major axis of an elliptical point contact footprint [31-34]. This is unlike the case for balls-raceway groove contacts where lubricant entrainment occurs along the minor axis of an elliptical contact footprint. For hypoid gear teeth, inlet lubricant entrainment often occurs at an angle to the elliptical footprint axes.

The contact of cam-follower pairs in many applications such as vehicular valve train systems also operate in EHL, where for a flat tappet, the contact is of finite line contact geometry [35-38] and for the cam-roller follower is an elliptical point contact [39-42]. 
It turns out that many other load bearing conjunctions, other than the aforementioned concentrated contacts of ellipsoidal solids of revolution, also operate under EHL, including many endo-articular natural or replacement joints as noted by Dowson and his co-workers [43-45]. In these cases, the larger contact areas and the surfaces of lower elastic modulus lead to lower generated pressures, a regime of lubrication which is often referred to as soft EHL, as opposed to the aforementioned high pressure contacts, which are regarded as hard EHL. One thing that all the foregoing areas of EHL research have in common is the pioneering contributions of Dowson in almost all of them. He noted that EHL has been nature's own choice for the lubrication of joints and many other biological systems [44]. Yet, as Dowson [46] also noted, the knowledge concerning EHL is still evolving. This is mainly because of the complex multi-physics nature of EHL, comprising thermo-piezo-viscous shear of often complex rheological fluids/lubricants and mechanisms of pressure and heat generation, which are affected by contact geometry, surface topography and often quite complex contact kinematics. The noted literature is only a sample of considerable research carried out since the original postulate of elastohydrodynamics first put forward by Ertel and Grubin [47].

Contact kinematics has a profound effect upon generated pressures and lubricant film formation, its shear characteristics, and thus the friction and energy efficiency of load bearing and power transmitting tractive contacts. In particular, contact kinematics is caused by changes in system dynamics. These are not often taken into account in mostly steady state studies, but are critical to the optimal operation of many machines. For example, stop-start or reciprocating motions or inlet reversals affect the elastohydrodynamic conditions as well as the mutual convergence and separation of mating members as in the squeeze film motion [48-50].

Jalali-Vahid et al. [48] compared numerical predictions with optical interferometric results of Ren at al [49], who considered both point and line contact geometries with sinusoidal variations in the applied load at a fixed speed of entraining motion. The authors showed that dynamic changes in the applied load induce the squeeze film action which significantly affects the lubricant film thickness. The formation of a squeeze-cave or elastic dimple was noted during the load varying cycle, increasing the film thickness compared with an equivalent steady state or quasi-static conditions, where EHL films are insensitive to applied load. A study conducted by Wang et al. [50] included sinusoidal variations in lubricant entrainment speed with a constant applied contact load. Similar conclusions to that of Ren et al. [49] were noted. In this case, the rise and fall of entraining velocity introduces a contact squeeze film effect as was shown clearly by Al-Samieh et al. [51] when studying the impact of ellipsoidal solids. Their findings agreed well with the measured pressures of the impact of a ball on an oily plate by Safa and Gohar [52]. Transient conditions can also occur under impacting conditions. Following on from Safa and Gohar [52], Dowson and Wang [53] developed a numerical model, considering the squeeze effect to replicate the motion of a bouncing elastic ball on an oil covered plate. The predictions showed good agreement with the observations made by Safa and Gohar [52]. Wang et al. [54] solved an impact EHL analysis under transient conditions for a range of different contact ellipticities, while Fryza et al. [55] experimentally studied EHL contacts created under impact with a range of kinematics and different types of lubricants.

Transience is also caused by changes in contact geometry, for example during a meshing cycle of a pair of gear teeth. Geometrical changes in contacting surfaces alter the kinematics of contact, which in turn change the speed and direction of the lubricant entraining motion, often occurring at an angle to the axes of the elliptical point contact footprint. This problem has been studied by a number of researchers [31,56-58]. The contact of a pair of gear teeth during a meshing cycle implies that the contact footprint undergoes precession of its centre, as shown by Mohammadpour et al. [59,60]. There is a dearth of EHL analysis of contacts subject to spinning motion. An early study of point contact EHL under pure spin condition was reported by Mostofi and Gohar [61]. They showed that the influence of spin becomes significant at higher angular velocities. Li et al. [62] showed that at higher loads, the film thickness, and particularly the location and magnitude of the contact side lobes, are influenced by any spinning motion of the contacting solids. 
This paper presents the influence of the normal approach and separation (squeeze film motion) of lubricated contacting solids of revolution under transient EHL, coupled with the contact spinning motion-an approach not hitherto reported in literature.

\section{Methodology}

\subsection{Governing Equations}

Reynolds equation for the general case of the two-dimensional analysis of contacts under rolling, sliding and squeeze film motions is stated as:

$$
\frac{\partial}{\partial x}\left[\frac{\rho h^{3}}{6 \eta}\left(\frac{\partial p}{\partial x}\right)\right]+\frac{\partial}{\partial y}\left[\frac{\rho h^{3}}{6 \eta}\left(\frac{\partial p}{\partial y}\right)\right]=\frac{\partial(\rho h U)}{\partial x}+\frac{\partial(\rho h V)}{\partial y}+\frac{\partial(2 \rho h)}{\partial t}
$$

where $p, h, \eta$ and $\rho$ are pressure, film thickness, lubricant dynamic viscosity and density, respectively. $x$ denotes the direction along the minor axis of an elliptical point contact footprint, whilst $y$ is along the direction of its major axis. The surface speeds along the minor and major axes are given as:

$$
\begin{aligned}
& U=2 u_{e} \cos \theta \\
& V=2 u_{e} \sin \theta
\end{aligned}
$$

where $\theta$ is the angle of the inlet lubricant entrainment velocity $u_{e}$ with the minor axis of the elliptical point contact footprint.

The term $\partial(2 \rho h) / \partial t$ represents the squeeze film effect and retains the film memory or lubricant film transience with time.

The elastic film shape is given as:

$$
h(x, y)=h_{0}+s(x, y)+\delta(x, y)
$$

where $h_{0}$ is the original/minimum clearance between the undeformed contiguous solids in contact and $s$ is the geometric profile of an equivalent instantaneous ellipsoidal solid of revolution, representing the two profiled contacting bodies in contact (Figure 1):

$$
s=\frac{x^{2}}{2 R_{z x}}+\frac{y^{2}}{2 R_{y z}}
$$

with a flat elastic half space of effective (equivalent) modulus of elasticity $E^{\prime}$ :

$$
\frac{2}{E^{\prime}}=\frac{1-v_{1}^{2}}{E_{1}}+\frac{1-v_{2}^{2}}{E_{2}}
$$

where $E_{1,2}$ and $v_{1,2}$ are the Young's moduli of elasticity and Poisson's ratios of the contacting pairs. $R_{z x}$ and $R_{z y}$ are the principal radii of the equivalent ellipsoidal solid in the planes of contact $\mathrm{zx}$ and $\mathrm{zy}$, respectively ( $\mathrm{z}$ is the direction into the depth of contact, Figure 1 shows the instantaneous ellipsoidal solid for the case of the ball-raceway contacts studied in this paper):

$$
\frac{1}{R_{z x}}=\frac{1}{R_{x 1}}+\frac{1}{R_{x 2}}, \ldots \frac{1}{R_{z y}}=\frac{1}{R_{y 1}}+\frac{1}{R_{y 2}}
$$



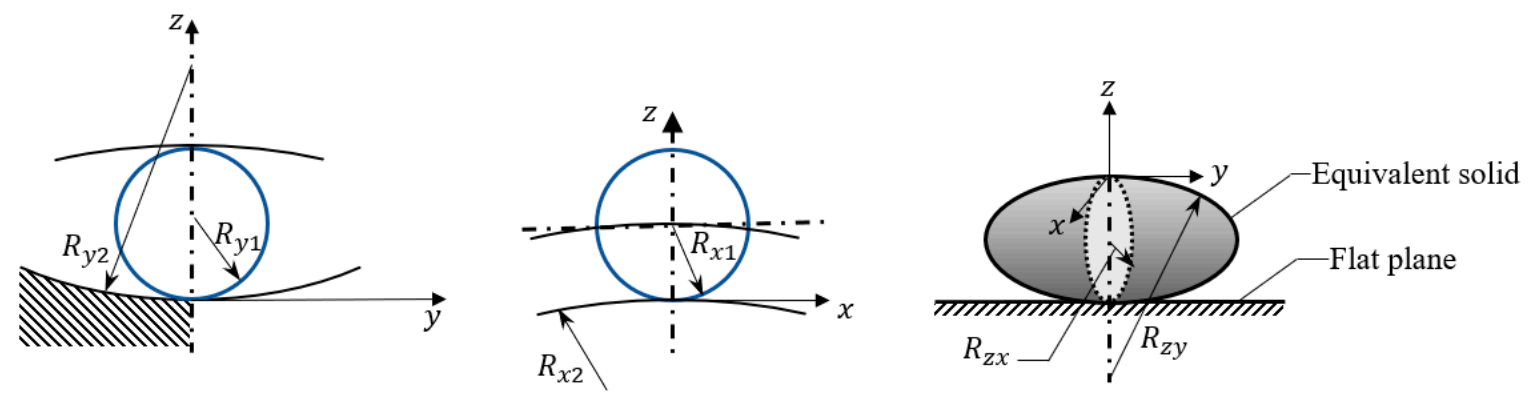

Figure 1. The effective ellipsoidal solid of revolution contacting a semi-infinite elastic half-space.

Localized elastic contact deflection $\delta$ is obtained through the use of elasticity potential (Equation (8)). Thus [7,63]:

$$
\delta\left(x^{\prime}, y^{\prime}\right)=\frac{2}{\pi E^{\prime}} \iint \frac{p(x, y)}{\sqrt{\left(x-x^{\prime}\right)^{2}+\left(y-y^{\prime}\right)}} d x d y
$$

where $x$ and $y$ denote the positions of the generated pressure elements, whilst $x^{\prime}$ and $y^{\prime}$ denote the location of points of localised contact deflection.

Lubricant viscosity alters with pressure and temperature. For an isothermal analysis, this relationship can be approximated by [64]:

$$
\eta=\eta_{0} \exp \left\{\ln \left(\frac{\eta_{0}}{\eta_{r}}\right)\left[\left(1+\frac{p}{p_{r}}\right)^{Z}-1\right]\right\}
$$

where $\eta_{0}$ is the atmospheric viscosity of the lubricant and $\eta_{r}$ and $p_{r}$ are $6.31 \times 10^{-5}$ and $1.9609 \times 10^{8}$, respectively, for some mineral and synthetic oils.

The piezo-viscosity index, $Z$, is:

$$
Z=\frac{\alpha_{0} p_{r}}{\ln \left(\frac{\eta_{0}}{\eta_{r}}\right)}
$$

where the experimentally determined pressure-viscosity coefficient is denoted by $\alpha_{0}$.

A more precise and lubricant-specific characterisation of variation of viscosity with pressure may be achieved using data from high pressure rheometry, including the shear-thinning behaviour of the lubricant [65-69]. This is particularly important at higher contact pressures, given the limitations of the Roelands' relationship. In the absence of such data for the lubricants used in the various parts of this study, a rather generic lubricant constitutive relationship is employed here. Furthermore, a thermal EHL analysis would be more representative of the real contact conditions, but the measurements/observations used for the purpose of validation/comparison are carried out/reported under isothermal conditions.

Changes in lubricant density with pressure for isothermal conditions are provided by Dowson and Higginson [2] as:

$$
\rho=\rho_{0}\left(1+\frac{0.6 \times 10^{-6} p}{1+1.7 \times 10^{-9} p}\right)
$$

where $\rho_{0}$ is the density at atmospheric pressure and at a reference temperature.

\subsection{Method of Solution}

The solution to the EHL problem was undertaken using the finite difference method. A simultaneous solution of Reynold's equation, elastic film shape and rheological state equations were required. The effective Influence Newton-Raphson (EIN) low relaxation method was employed as outlined by Jalali-Vahid et al. [48]. This is a well-established and robust numerical solution methodology and has been successfully used for solving EHL problems in contacts with loads exceeding $4 \mathrm{kN}$ in the case of hypoid gear pairs used in automotive differential units $[59,70]$. Therefore, the method was deemed 
to be suitable for the current study considering that the applied loads were much lower in the current described cases. Nevertheless, a multi-grid discretisation method would be expected to provide more stable numerical results, particularly at high loads. The following procedure was used:

1. The input variables included contact geometry, lubricant rheological data, material properties, and operating conditions including loading conditions and contact kinematics.

2. An initial guess was made for the minimum gap (film thickness), $h_{0}$, at the centre of the contact. For the initial step in the iterative process, a steady state rolling and sliding condition was assumed (i.e., $\frac{\partial h}{\partial t}=0$ ). Clearly, the squeeze film term was updated in an iterative manner as: $\frac{\partial h}{\partial t}=\left(h_{i, j}^{n}-h_{i, j}^{n-1}\right) / \Delta t$, where $(i, j)$ is any location within the computational domain, and $\mathrm{n}$ represents the iteration index in any step of computation $\Delta t$.

3. The computational domain with geometric definitions is shown in Figure 2. $f_{i}$ and $f_{o}$ are the inlet and exit boundary distances from the centre of the Hertzian region of the contact, defining the computational domain, whilst $f_{s 1}$ and $f_{s 2}$ define the domain in the lateral side leakage direction.

4. The computed generated contact pressures were updated in the low relaxation EIN iterative process with $\Omega=10^{-2}-10^{-1}$ as:

$$
p^{n}=p^{n-1}+\Omega \Delta p^{n} .
$$

5. The following pressure convergence criterion was used, where the limit of convergence wastypically in the range: $\varepsilon_{p}=10^{-5}-10^{-4}$ :

$$
\sum_{i} \sum_{j}\left|\frac{p_{i, j}^{n}-p_{i, j}^{n-1}}{p_{i, j}^{n}}\right| \leq \varepsilon_{p}
$$

6. The load carrying capacity $W$ (contact reaction) was obtained over the computational domain as:

$$
W=\iint p d x d y
$$

7. This instantaneous contact reaction should equate the applied contact load, W. The load convergence criterion was:

$$
\left|\frac{W-W_{p}}{W}\right| \leq \varepsilon_{w}
$$

where the load limit of convergence was usually in the range: $\varepsilon_{w}=10^{-5}-10^{-3}$.

8. If the convergence criterion (15) was not satisfied, the film thickness was updated, and the entire procedure was repeated:

$$
h_{0}=h_{0}\left(\frac{W_{p}}{W}\right)^{\varsigma}
$$

where $\varsigma$ is a damping/load relaxation factor. For the quasi-static analysis reported here: $\varsigma=0.1$, and for transient conditions: $\varsigma=0.005$.

9. For transient cases, the load and speed of lubricant entrainment were updated and the squeeze film term computed as stated in step 2.

10. Steps 4 to 10 were repeated until 5 iterative cycles were made in any transient analysis. 


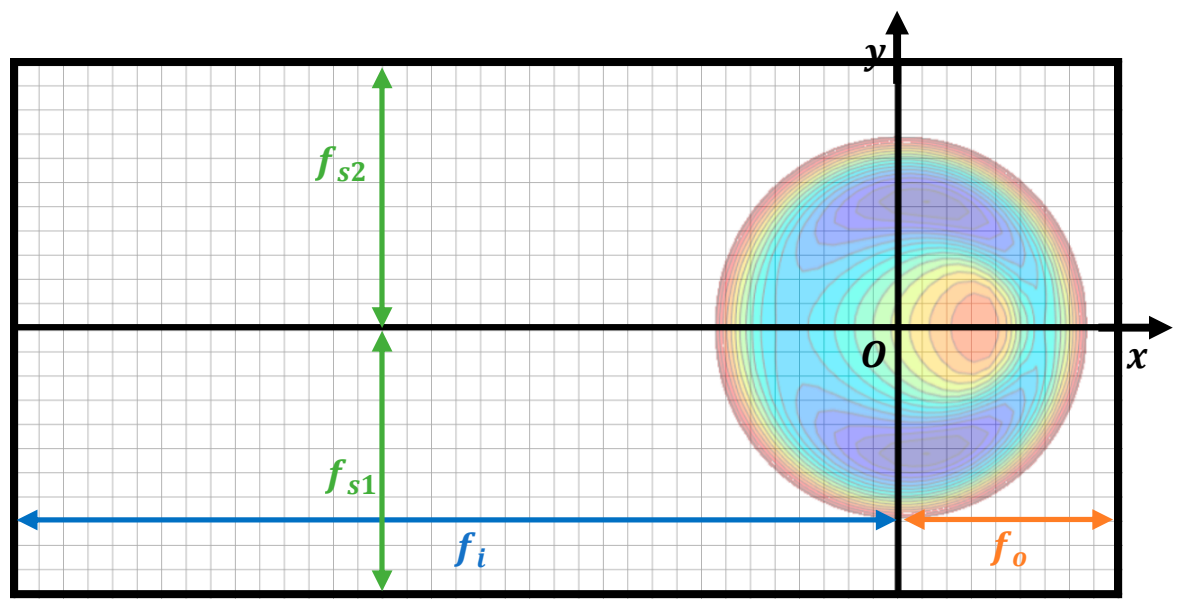

Figure 2. Computational domain.

Table 1 lists the dimensions of the computational domain used in the current analyses.

Table 1. Domain definitions.

\begin{tabular}{ccc}
\hline Parameter & Symbol & Value \\
\hline Inlet distance & $f_{i}$ & $3.5 a-7.5 a$ \\
Exit boundary & $f_{o}$ & $1.5 a$ \\
Side Length & $f_{s 1}, f_{s 2}$ & $1.5 b$ \\
\hline
\end{tabular}

It should be noted that, for most cases, the number of elements across the transverse direction was chosen such that: $d x=d y$. Moreover, the inlet and exit lengths chosen were based on the works of Chittenden et al. [31] and Hamrock and Dowson [71] for fully flooded conditions.

With regard to contact kinematics, based on pure spin, the same conditions as that reported by Mostofi and Gohar [61] were used. The computational domain for this case is shown in Figure 3. The domain was split into 4 quadrants with the centre of precession and that of the contact remaining coincident. Thus, under pure spin, the surface speeds along the minor and major axes were obtained as:

$$
\begin{aligned}
& u_{s}=\omega r_{s} \sin \phi \\
& v_{s}=\omega r_{s} \cos \phi
\end{aligned}
$$

where $\omega$ is the average angular velocity of the two bodies in contact, and $r_{s}$ is the radial distance from the centre of the contact. The instantaneous angle that $r_{s}$ makes with the minor axis of the elliptical point contact footprint is denoted by $\phi$.

Thus, the final surface speeds needed to be modified, depending on the quadrant of the computational domain. For example, quadrant 1 had surface speeds along the minor $U_{s}$ and major $V_{s}$ axes as:

$$
\begin{gathered}
U_{s}=U-2 u_{s} \\
V_{s}=V+2 v_{s} .
\end{gathered}
$$




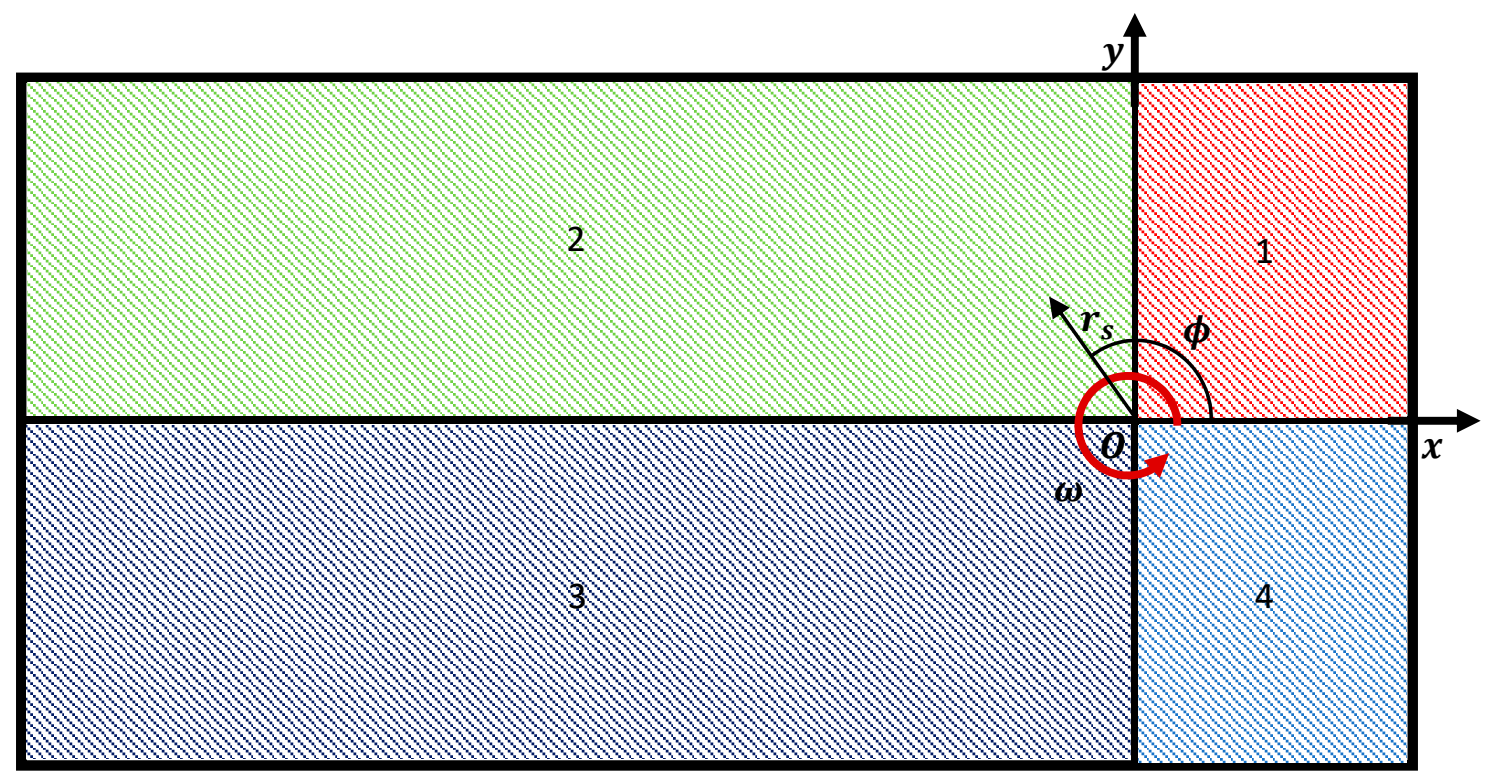

Figure 3. Computational domain with spin coordinates.

\section{Validation of Methodology}

The first step was to validate the expounded methodology in Section 2, prior to any further detailed analysis, which included transient conditions involving squeeze film and spin motions.

There was a dearth of measurements and predictive analyses in such cases which invariably occur in practice such as squeeze film motion in converging and separating gear meshing teeth pairs combined with the spin (precession) of the contact footprint. The analysis of the combined spin and squeeze film motions is a major contribution of this paper.

\subsection{Steady State Angled Flow Entrainment}

As the first step in the validation process, comparisons were made with the optical interferometric observations in [56,57], who studied the film thickness and shape for a ball rolling and sliding in a groove. Under these conditions, the lubricant entrainment into the contact occurred at an angle $\theta$ to the minor axis of the elliptical point contact footprint. Tables 2 and 3 list the contact geometrical data, lubricant rheology and the operating conditions, where the dimensionless parameters defining the operating conditions (material combination, speed and load parameters) were:

$$
G_{e}=\alpha_{0} E^{\prime}, U_{e}=\eta_{0} u_{e} / E^{\prime} R_{e}, W_{e}=W / E^{\prime} R_{e}^{2}, H^{*}=h / R_{e}
$$

where the equivalent radii of curvature in the direction of entraining motion, $R_{e}$, and that in the side leakage, $R_{s}$, were obtained as:

$$
\begin{aligned}
& \frac{1}{R_{e}}=\frac{\cos ^{2} \theta}{R_{z x}}+\frac{\sin ^{2} \theta}{R_{z y}} \\
& \frac{1}{R_{s}}=\frac{\sin ^{2} \theta}{R_{z x}}+\frac{\cos ^{2} \theta}{R_{y z}}
\end{aligned}
$$


Table 2. Lubricant and geometry properties [56,57].

\begin{tabular}{cccc}
\hline Parameter & Symbol & Value & Units \\
\hline Viscosity (at $21.7^{\circ} \mathrm{C}$ ) & $\eta_{0}$ & 3 & $\mathrm{~Pa} \cdot \mathrm{s}$ \\
Pressure coefficient of viscosity & $\alpha_{0}$ & $2.5 \times 10^{-8}$ & $1 / \mathrm{Pa}$ \\
Density (at $21.7^{\circ} \mathrm{C}$ ) & $\rho_{0}$ & 890 & $\mathrm{~kg} / \mathrm{m}^{3}$ \\
Radius of curvature along minor axis & $R_{z x}$ & 0.0127 & $\mathrm{~m}$ \\
Radius of curvature along major axis & $R_{z y}$ & 0.0853 & $\mathrm{~m}$ \\
\hline
\end{tabular}

Table 3. Operating conditions [56,57].

\begin{tabular}{cccc}
\hline $\boldsymbol{\theta}$ & $\boldsymbol{U}_{\boldsymbol{e}}$ & $\boldsymbol{W}_{\boldsymbol{e}}$ & $G_{\boldsymbol{e}}$ \\
\hline $0^{\circ}$ & $6.00 \times 10^{-12}-$ & $4.67 \times 10^{-8}-4.67 \times 10^{-7}$ & \\
& $8.87 \times 10^{-11}$ & & 3578 \\
$67^{\circ}$ & $3.35 \times 10^{-12}-$ & $8.41 \times 10^{-8}-6.02 \times 10^{-8}$ & \\
& $3.38 \times 10^{-11}$ & & \\
$82^{\circ}$ & $3.37 \times 10^{-12}-$ & $2.21 \times 10^{-8}-2.96 \times 10^{-8}$ & \\
\hline
\end{tabular}

The lubricant used in Thorp [57] is BP 1065, a mineral oil of high viscosity cylinder stock [72]. The relevant data are listed in Table 2.

Figure 4 shows a comparison between optical interferometric measurements of Thorp and Gohar [53] and the predictions of the current analysis using a steady state solution of the problem (i.e., $\partial h / \partial t=0$ in Equation (1)). The results are plotted in the $\left(L^{*}, K^{*}\right)$ domain, where [54]:

$$
\begin{gathered}
L^{*}=\frac{U_{e}}{W_{e}^{1.5} G_{e}^{0.5}} \\
K^{*}=\frac{H^{*}}{W_{e} G_{e}}
\end{gathered}
$$

For practical purposes, Thorp [57] chose a similar non-dimensional group such that a simple linear relationship, dependent on contact kinematics and film thickness, could be obtained. For the purposes of consistency and ease of comparison, the presentation of current results follows in the same manner. It is noted that when the lubricant inlet flow occurred along the minor axis of the elliptical point contact footprint (i.e., $\theta=0$ ), the central film thickness conformed very closely to that measured in [57]. For the angled flow cases, the minimum film thickness agreed closer with the measured values. In general, good agreement was obtained between the predictions of the current analysis and the measured film thickness in [56,57].

Comparisons of the computed lubricant film thickness contours with the corresponding photomicrographs of Thorp [56,57] are shown in Figures 5-7. Good agreement was observed in all cases. 
(a)

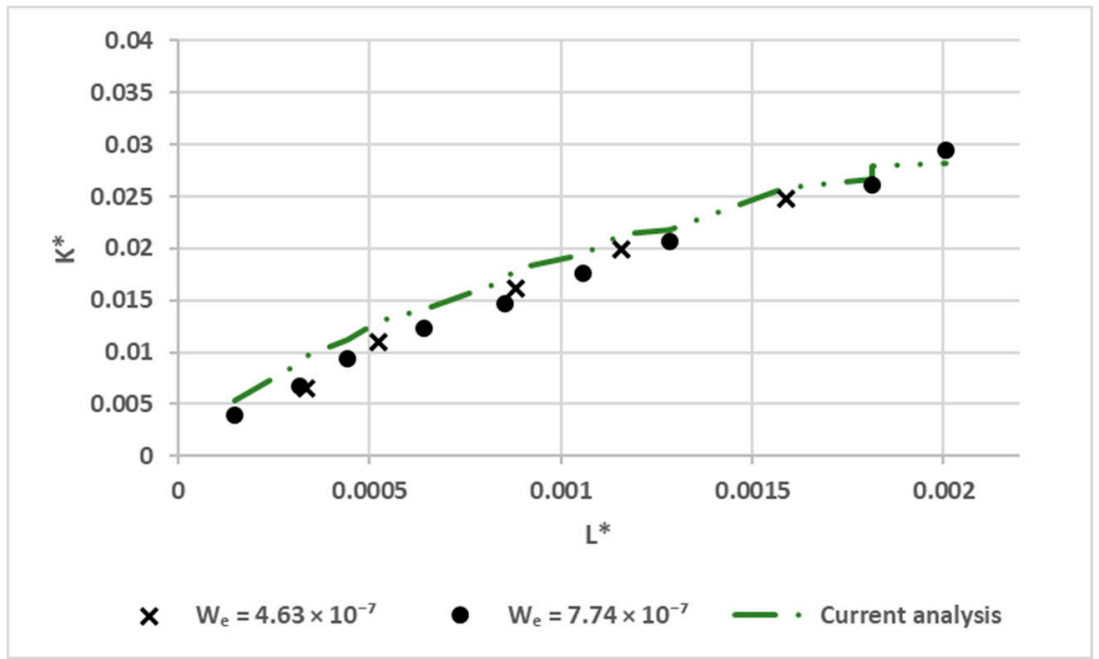

(b)

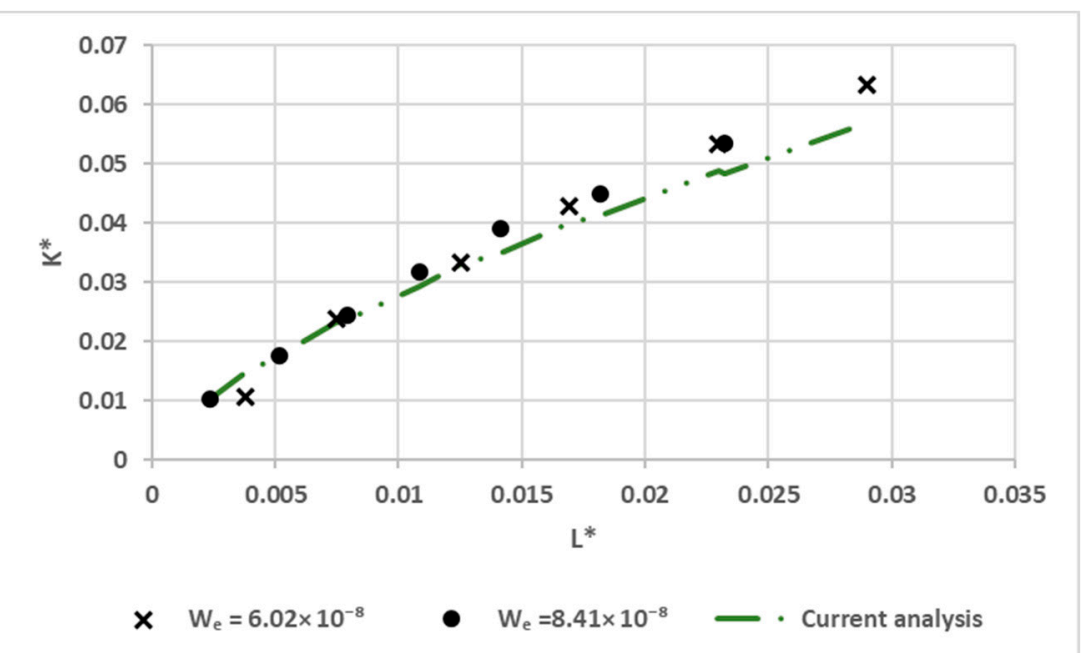

(c)

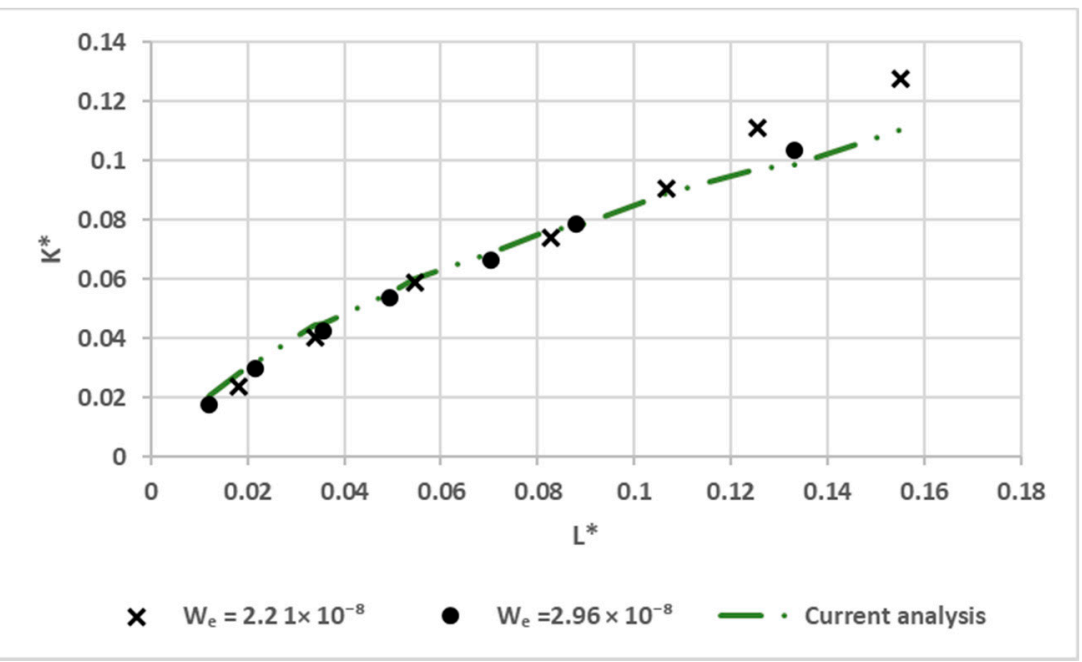

Figure 4. Comparisons with the measurements in [56,57]: (a) $\theta=0^{\circ}$, (b) $\theta=67^{\circ}$ and (c) $\theta=82^{\circ}$. 
(a)

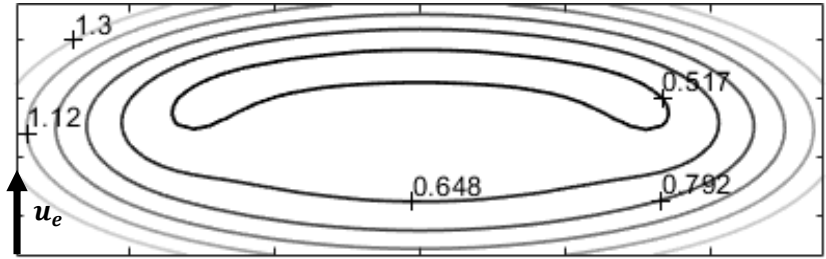

(b)

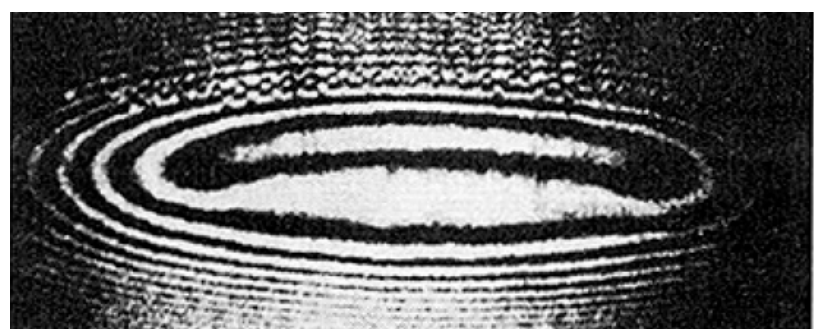

Figure 5. Comparisons of contours of $h(\mu \mathrm{m})$ for: $\theta=0^{\circ}$ (flow along minor axis), $U_{e}=3.59 \times 10^{-11}$, $W_{e}=1.34 \times 10^{-8}, G_{e}=3578 ;(\mathbf{a})$ current analysis, (b) photomicrograph $[56,57]$.

(a)

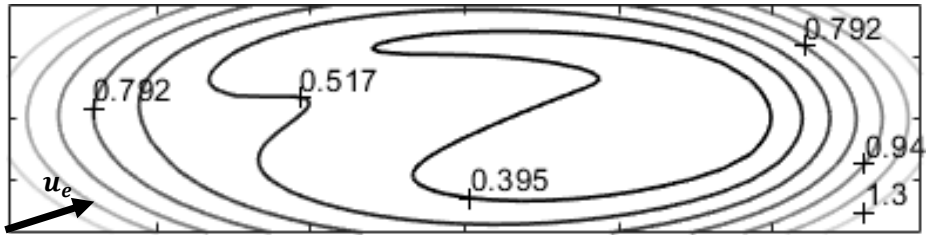

(b)

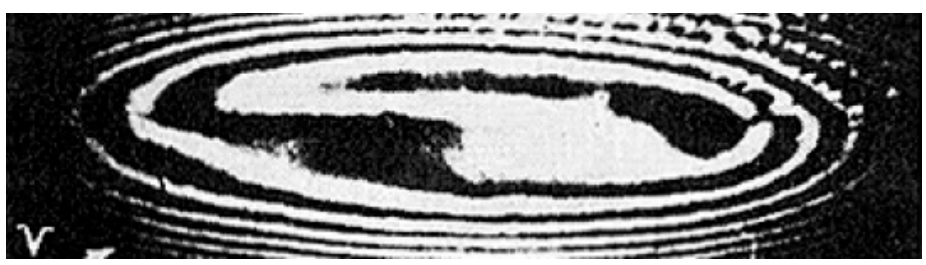

Figure 6. Comparison of contours of $h(\mu \mathrm{m})$ for: $\theta=67^{\circ}, U_{e}=5.55 \times 10^{-11}, W_{e}=1.34 \times 10^{-8}$, $G_{e}=3578 ;$ (a) current analysis, (b) photomicrograph [56,57].

(a)

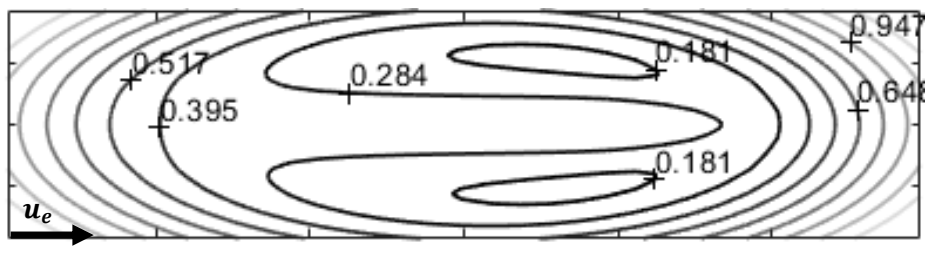

(b)

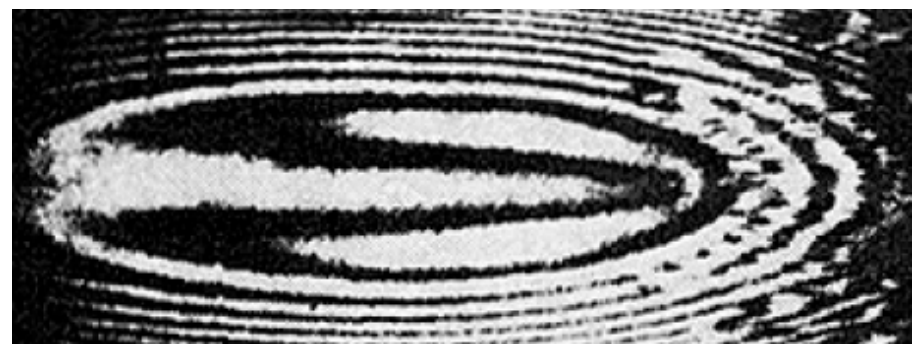

Figure 7. Comparison of contours of $h(\mu \mathrm{m})$ for: $\theta=90^{\circ}$ (flow along major axis), $U_{e}=2.28 \times 10^{-11}, W_{e}=1.34 \times 10^{-8}, G_{e}=3578$, contours of $h(\mu \mathrm{m}) ;(\mathbf{a})$ current analysis, (b) photomicrograph $[56,57]$. 


\subsection{Steady-State Spin}

Mostofi and Gohar [61] were one of the first to explore spin in the EHL elliptical point contacts, particularly at relatively high angular velocities. Here, comparisons were made with their findings. Lubricant rheological properties and the material parameter used for the case of pure spin analysis are listed in Table 4, whilst Table 5 lists the contact operating conditions.

Table 4. Lubricant and material properties [61].

\begin{tabular}{cccc}
\hline Parameter & Symbol & Value & Units \\
\hline Dynamic viscosity (at $\left.21.7^{\circ} \mathrm{C}\right)$ & $\eta_{0}$ & 3 & $\mathrm{~Pa} \cdot \mathrm{s}$ \\
Pressure-viscosity coefficient & $\alpha_{0}$ & $1.51 \times 10^{-8}$ & $1 / \mathrm{Pa}$ \\
Density (at $21.7^{\circ} \mathrm{C}$ ) & $\rho_{0}$ & 890 & $\mathrm{~kg} / \mathrm{m}^{3}$ \\
Non-dimensional material parameter & $\mathrm{G}_{e}$ & 1799 & - \\
\hline
\end{tabular}

Table 5. Contact operating conditions [61].

\begin{tabular}{cccc}
\hline Parameter & Symbol & Value & Units \\
\hline Load & $W$ & 6.91 & $\mathrm{~N}$ \\
Initial entrainment speed & $u_{e}$ & 0.000145 & $\mathrm{~m} / \mathrm{s}$ \\
$\left(\theta=0^{\circ}\right)$ & $\omega$ & 61.9 & $\mathrm{rad} / \mathrm{s}$ \\
\hline Angular velocity & $\omega$
\end{tabular}

To be consistent with the domain definitions in [61], the major axis of the contact ellipse was set along the $x$ direction. For all other analyses in this paper, the $x$ direction was reserved for the direction of the minor axis of the elliptical point contact footprints. Figures 8 and 9 show the predictions of the current analysis and those in [61]. Good agreement was observed. Figure 8 shows the isobars of the non-dimensional pressure, given as:

$$
p^{*}=p / E^{*}
$$

where $E^{*}$ is the plane strain elastic modulus of a pair of identical material contacting surfaces (in this case steel), as defined in [61]:

$$
\frac{1}{E^{*}}=\left(1-v^{2}\right) / \pi E
$$

(a)
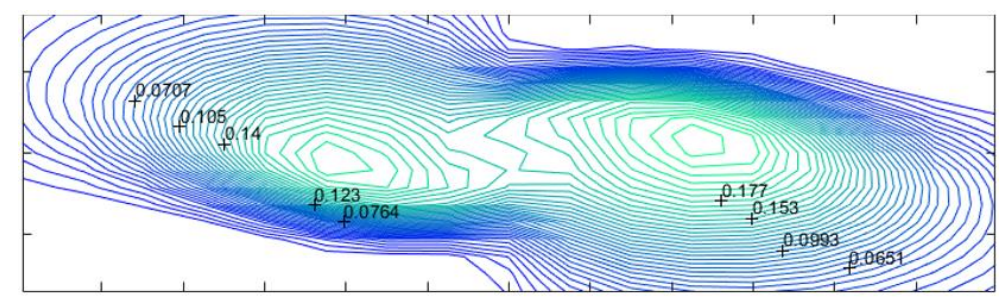

(b)

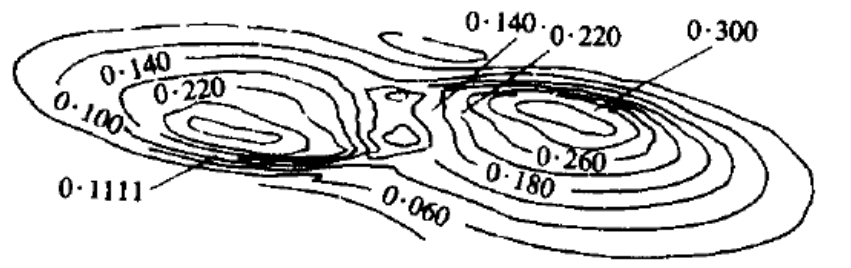

Figure 8. Dimensionless pressure isobar; (a) current analysis, (b) Mostofi and Gohar [61]. 
(a)

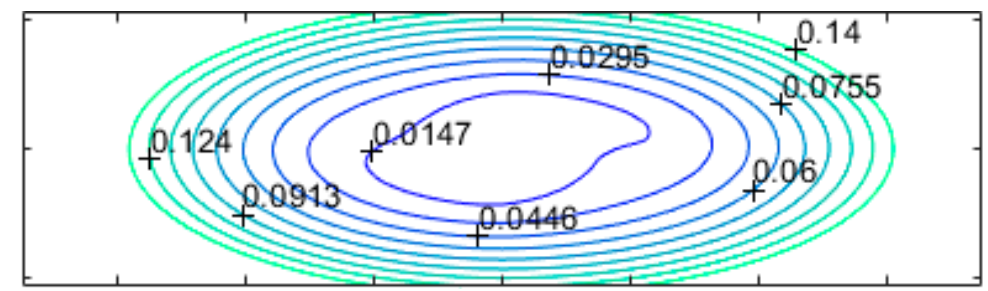

(b)

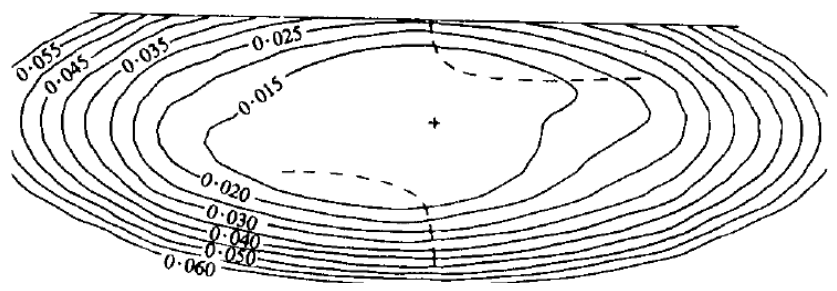

Figure 9. Dimensionless lubricant film thickness contours; (a) current analysis, (b) Mostofi and Gohar [61].

Figure 9 shows the corresponding contours of dimensionless film thickness: $h^{*}=\frac{h}{R_{e}} \times 10^{3}$.

The analysis thus far could be considered as quasi-steady as it did not include the effect of the squeeze film motion (i.e., the ultimate term on the right-hand side of Reynold's Equation (1)). The inclusion of this term made the solution time-dependent, thus the transient effects could be studied. Most contacts are subject to transience owing to variations in geometry, variations in contact kinematics and/or loading, such as in gear meshing, cam-follower cycle or indeed the orbital motion of balls or rollers in a bearing. Therefore, it was also important to validate the methodology for transient contact conditions.

\subsection{Transient Analysis}

Through optical interferometry, Wang et al. [50] observed the effect of induced squeeze film for a ball in pure rolling motion, subjected to short stoke reciprocations. They also used a multi-grid finite difference method for the solution of Equation (1) for the same reciprocating conditions as in their experiment. The contact surface speed alters in such a case in a sinusoidal manner:

$$
U=L \omega_{f} \sin \left(\omega_{f} t\right)
$$

where the short stroke-length is: $L=5 \times 10^{-4} \mathrm{~m}$, and $\omega_{f}=\frac{2 \pi}{T}=48.9 \mathrm{rad} / \mathrm{s}$ is the angular velocity chosen for the experiment. The load was kept constant at $39.2 \mathrm{~N}$ for the entire periodic cycle, $T$.

The modulus value of $U$ was used in Reynold's equation as the entraining motion was represented by a speed as a scalar quantity. This entrainment velocity variation in the reciprocating motion is shown in Figure 10. The squeeze film velocity, $\partial h / \partial t$, lagged behind the variation in inlet speed in line with cause and effect. However, the squeeze film response was only quasi-harmonic, thus the phase angle of lag was not $90^{\circ}$. Therefore, any increase in the inlet speed was followed by a rise in squeeze film velocity, and clearly by the separation of surfaces, leading to an increased film thickness. 


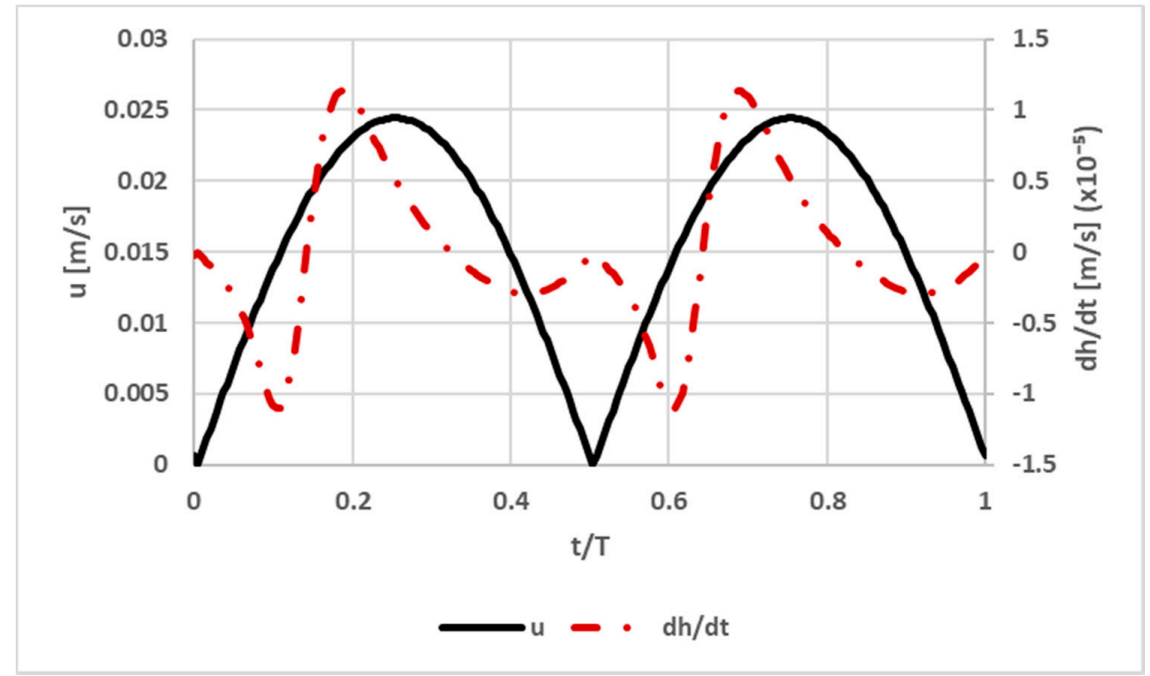

Figure 10. Squeeze film effect due to changes in speed of lubricant entraining motion.

The lubricant rheological and geometric contact properties are listed in Table 6.

Table 6. Lubricant and geometric properties [50].

\begin{tabular}{cccc}
\hline Parameter & Symbol & Value & Units \\
\hline Viscosity & $\eta_{0}$ & 1.22 & $\mathrm{~Pa} \cdot \mathrm{s}$ \\
Pressure coefficient of viscosity & $\alpha_{0}$ & $2.40 \times 10^{-8}$ & $1 / \mathrm{Pa}$ \\
Density & $\rho_{0}$ & 863 & $\mathrm{~kg} / \mathrm{m}^{3}$ \\
Radius of curvature & $R_{z x}=R_{z y}$ & 0.0127 & $\mathrm{~m}$ \\
\hline
\end{tabular}

Figure 11 shows a comparison of the current predictions with those of Wang et al. [62] for the positions of central contact and minimum exit film thickness for a cycle of period $\mathrm{T}$. In addition, the results in Figure 11a also show the variations in dimensionless central oil film thickness in a meshing cycle for different computational mesh densities. The differences in the computed results diminished as the mesh density increased to $75 \times 75$. Beyond that, the changes became insignificant as the mesh density increased further. Therefore, the mesh density of $75 \times 75$ was deemed to be sufficient for the purpose of the current analysis.

(a)

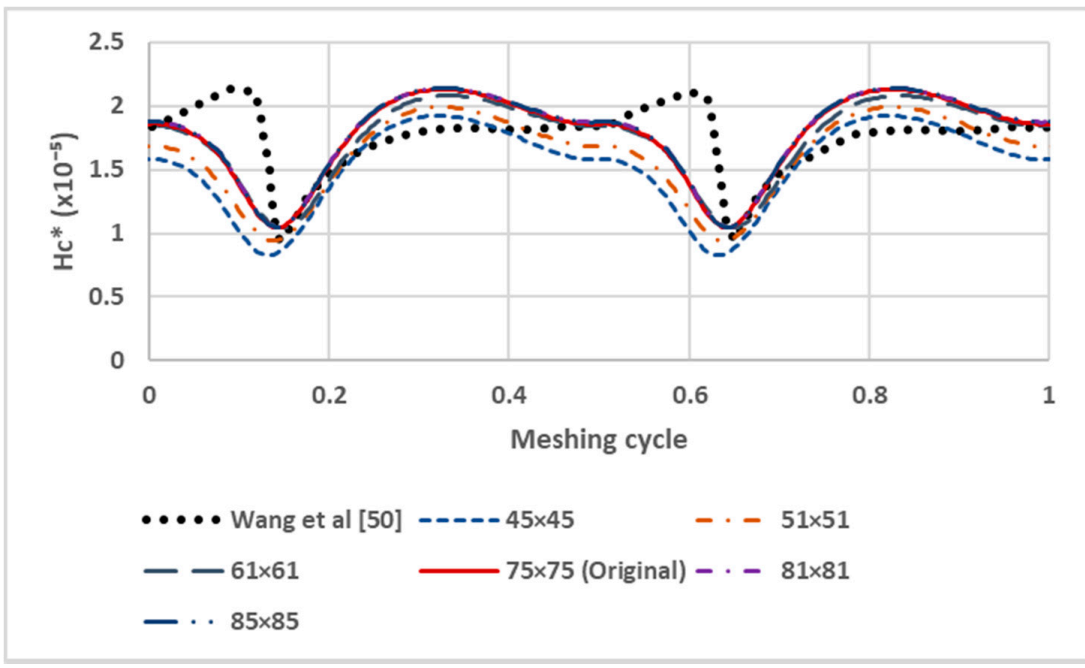

Figure 11. Cont. 
(b)

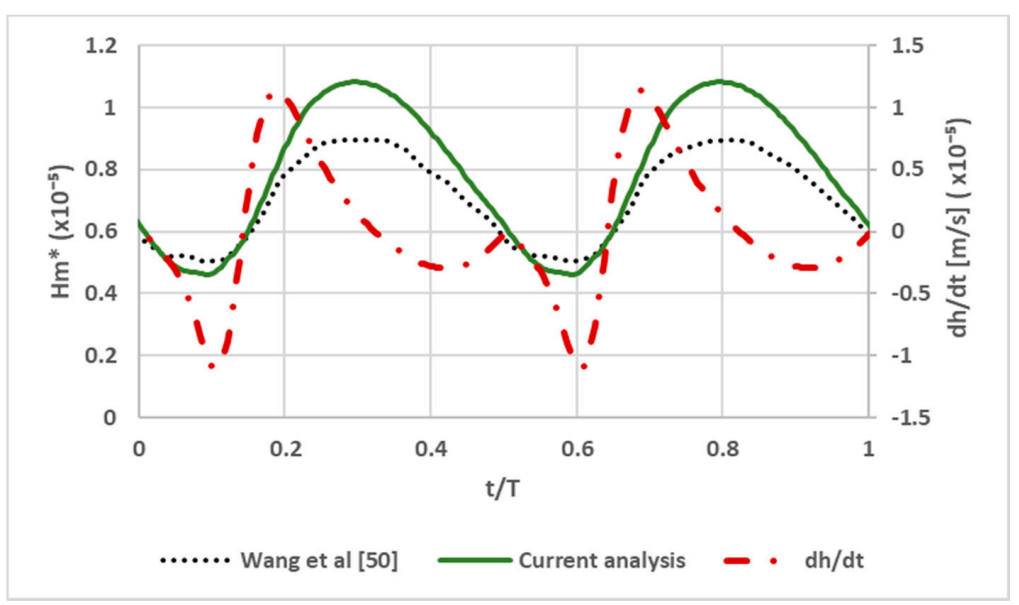

Figure 11. (a) Central and (b) minimum film thickness comparisons.

The overall magnitude and general trend of results were quite similar between the two computed results, but with deviations in certain feature variations, with a maximum divergence of $15 \%$. It is worth nothing that, Wang et al. [50] employed a multi-grid method with a total of 6061 elements as opposed to 5625 elements used in the current analysis using a fixed grid. There may be greater accuracy with finer meshes in parts of the multi-grid solution process. Nevertheless, the overall predictions conformed well with each other. Additionally, included in the figure is the variation of squeeze film velocity from Figure 10. This shows the aforementioned non-linear quasi-harmonic response of the lubricant film thickness, lagging behind $\partial h / \partial t$. As the squeeze film velocity increased, the lubricant film followed suit, with some delay.

Figure 12 shows that the transient film profile, predicted here throughout a reciprocation cycle, also conformed very well with the measured contact centreline film profiles constructed by Wang et al. [50] from their optical interferometric measurements.

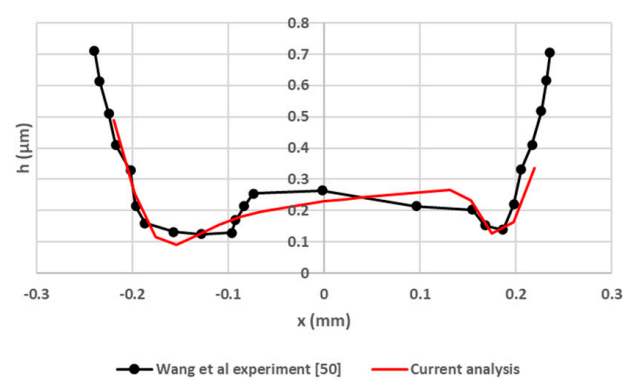

(a)

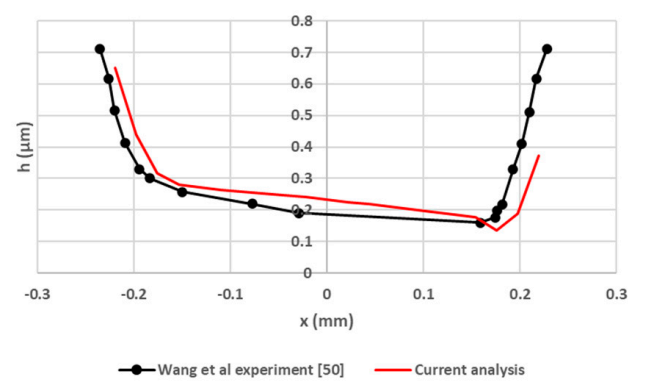

(c)

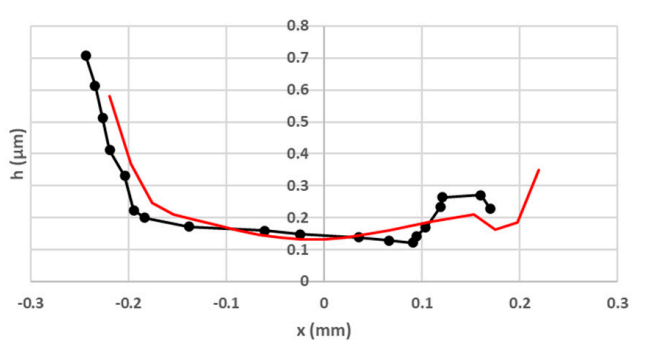

(b)

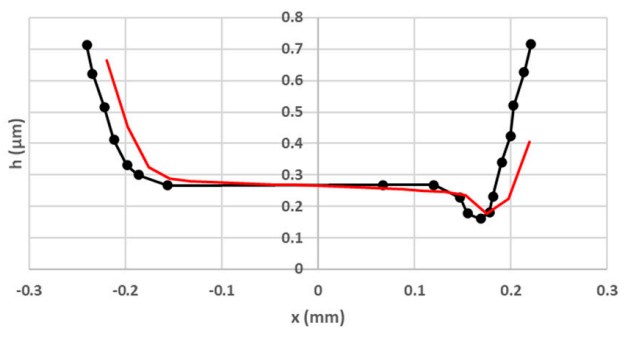

(d)

Figure 12. Cont. 


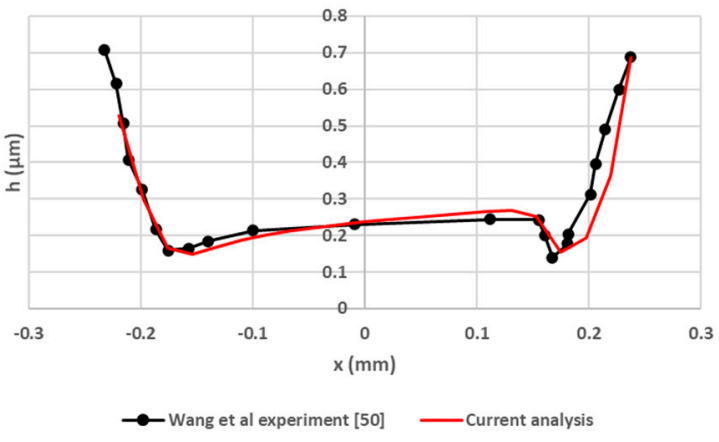

(e)

Figure 12. Transient contact centreline film thickness profile; current predictions and those measured by Wang et al. [62]: (a) $t / T=0.083$, (b) $t / T=0.167$, (c) $t / T=0.250$, (d) $t / T=0.333$ and (e) $t / T=0.417$.

\section{Transient EHL Subjected to Combined Rolling, Squeezing and Spinning Motions}

With the validated methodology for quasi-steady (Sections 3.1 and 3.2) and transient EHL (Section 3.3), an original contribution can be made for complex combined contact kinematics, involving rolling, squeezing, and spinning motions. The reciprocating motion in Wang et al. [50] can be used to enable combined rolling and squeeze film motions. Additional spinning action can be imposed on the contact. Such combined motions occur in many applications such as through a meshing cycle of a pair of hypoid gear teeth, where the elliptical point contact footprint is subjected to precession with respect to the entraining inlet lubricant flow [59]. Therefore, for this analysis, the Wang et al. [50] conditions, as stated in Table 6 and Equation (28), were used. Spinning motions of $\omega=30 \mathrm{rad} / \mathrm{s}$ and $\omega=61 \mathrm{rad} / \mathrm{s}$ were superimposed upon the same rolling and squeeze film motion as in the previous case. The higher value of $61 \mathrm{rad} / \mathrm{s}$ was the same as that used by Mostofi and Gohar [61].

Figure 13 shows the dimensionless minimum lubricant film thickness time histories for the various transient cases with different spin angular velocities, also including the case with no spin. Increasing spin decreased the lubricant film thickness, as it tends to push the lubricant out of the contact. However, the effect of spin was not as significant as the squeeze film motion, even though the spin velocities used here were quite large. The effect of spin was more pronounced in the absence of lubricant entrainment because of rolling/sliding motions. The results of the study by Mostofi and Gohar [61] showed significant changes to lubricant film thickness under high pure spin conditions.

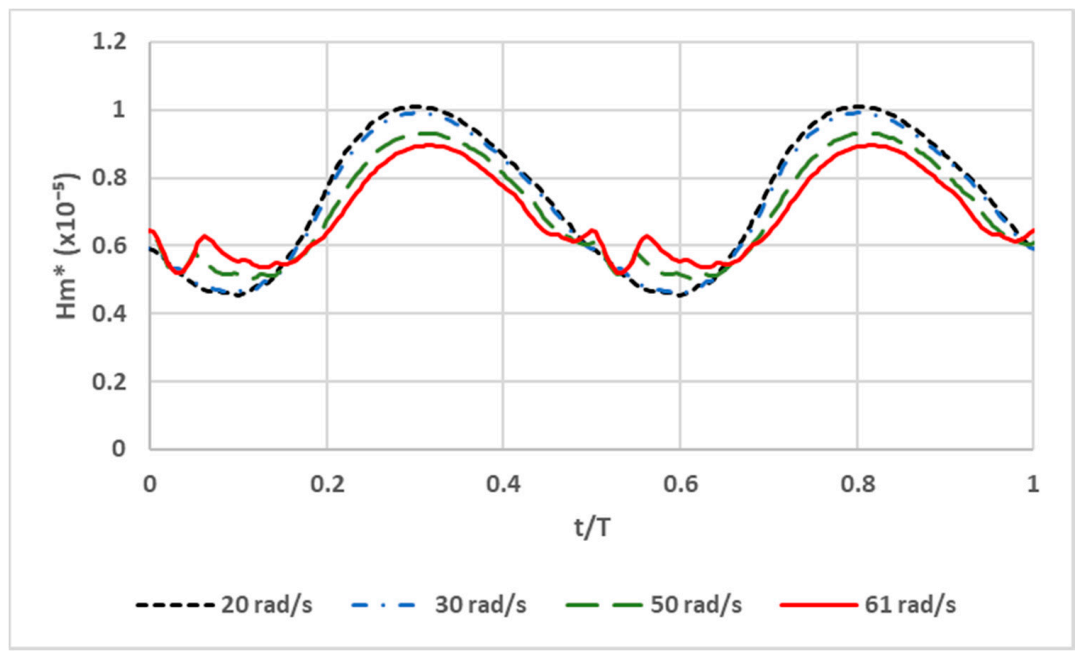

Figure 13. Minimum film thickness variation with different spin angular velocities. 
Clearly, spin altered the lubricant film thickness distribution within the contact as shown in the oil film thickness contours of Figure 14. With spin, the oil film thickness contours became asymmetric with the largest changes in film thickness occurring at the rear end sides of the contact which included the islands of minimum film thickness.

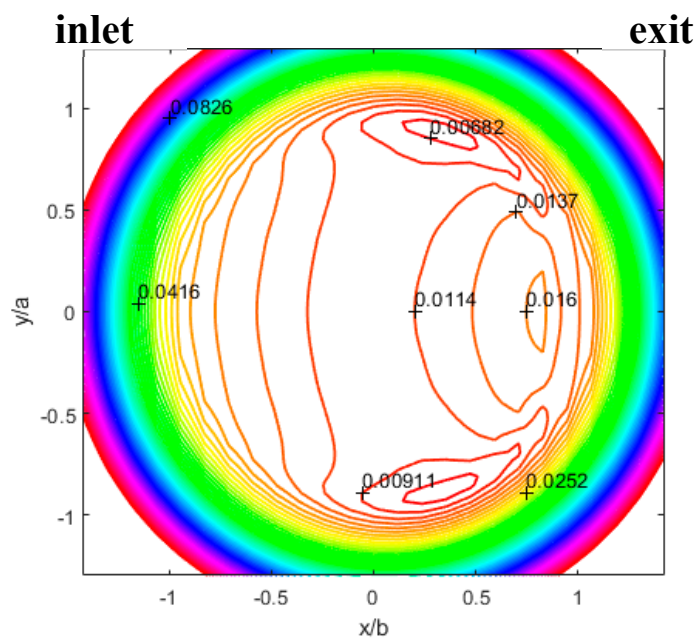

(a)

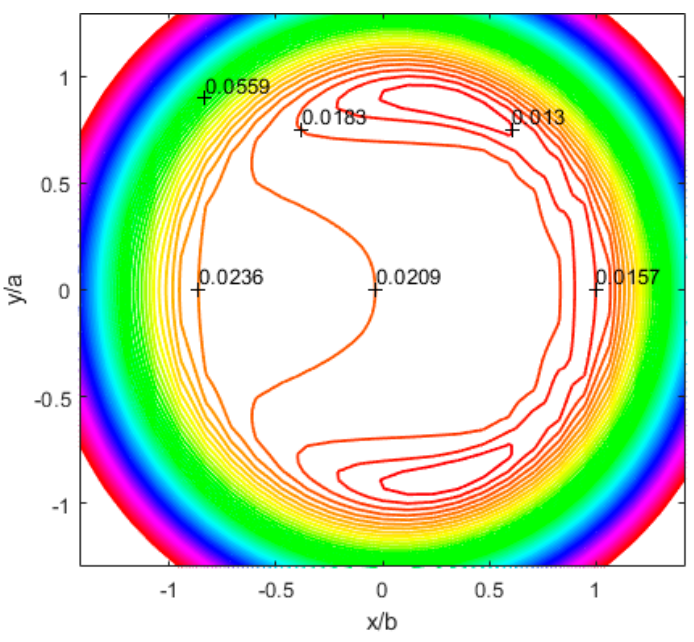

(c)

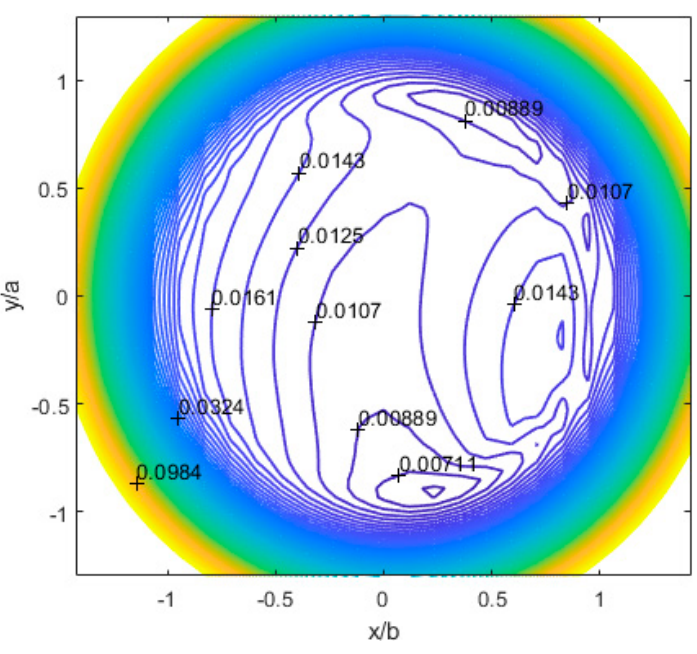

(b)

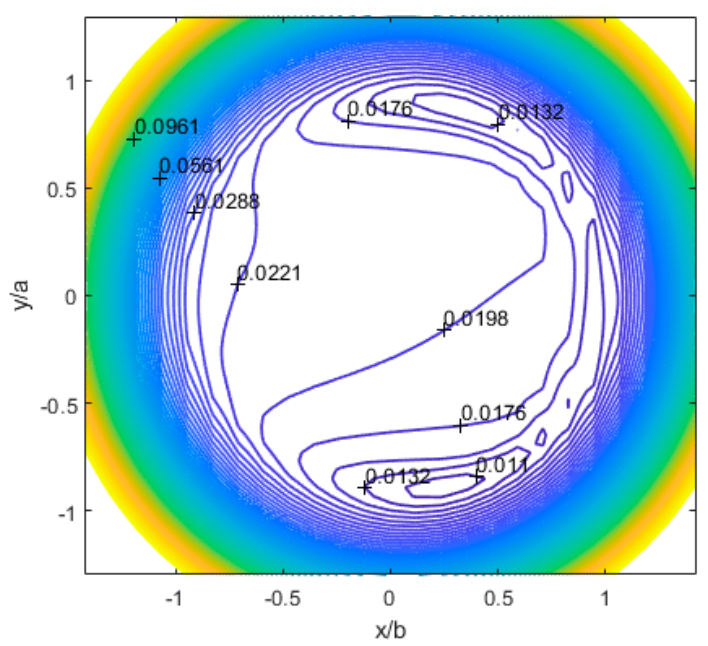

(d)

Figure 14. Dimensionless lubricant film thickness $\left(h / R_{e} \times 10^{3}\right)$ contours at 2 instances of the cycle with and without spin: (a) no spin and $t / T=0.167$, (b) $\omega=30 \mathrm{rad} / \mathrm{s}$ and $t / T=0.167$, (c) no spin and $t / T=0.333$, (d) $\omega=30 \mathrm{rad} / \mathrm{s}$ and $t / T=0.333$.

The results for lower spin speeds of 20 and $30 \mathrm{rad} / \mathrm{s} \mathrm{did} \mathrm{not} \mathrm{produce} \mathrm{similar} \mathrm{asymmetric} \mathrm{behaviour}$ to those at higher spins; 50 and $61 \mathrm{rad} / \mathrm{s}$. This can be explained in terms of the total entrainment speed into the contact domain, as shown in Figure 15. The total entrainment speed comprised the addition of the inlet entrainment speed due to reciprocating motion and an equivalent localised linear speed due to spin. The latter was calculated by multiplying the angular spin speed by the distance from the spin axis at any localised position within the contact footprint. Therefore, depending on the specified contact quadrant (see Figure 3), the spin-induced linear speed can either enhance the total entrainment speed or reduce it. Figure 15 shows that the addition of the spin resulted in a rise in the total entertainment speed into the contact in the region where an asymmetric behaviour for the minimum film thickness was observed, particularly at high spin velocities of 50 and $61 \mathrm{rad} / \mathrm{s}$. 


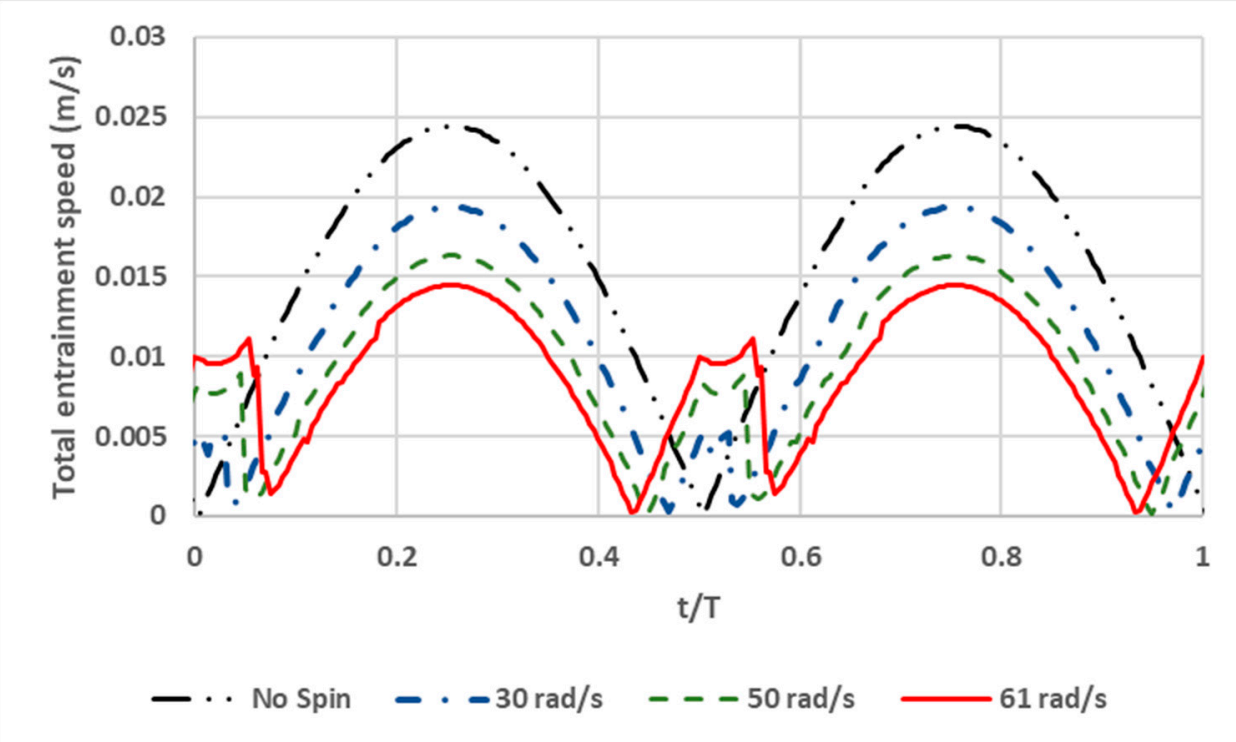

Figure 15. Variation of total entrainment speed during the cycle at the location of minimum film thickness.

Therefore, the existence of asymmetric film profiles can be attributed to the effect spin speed, promoting higher lubricant entrainment. This can also be elucidated further when considering the ratio of spin-induced linear speed to the inlet entrainment due to the reciprocating motion (Figure 16, for the instance: $t / T=0.0625)$. It can be seen that the effect of spin became dominant at higher spin speeds of 50 and $61 \mathrm{rad} / \mathrm{s}$. In particular, at $61 \mathrm{rad} / \mathrm{s}$, the effect of spin upon lubricant entrainment into the contact was dominant.

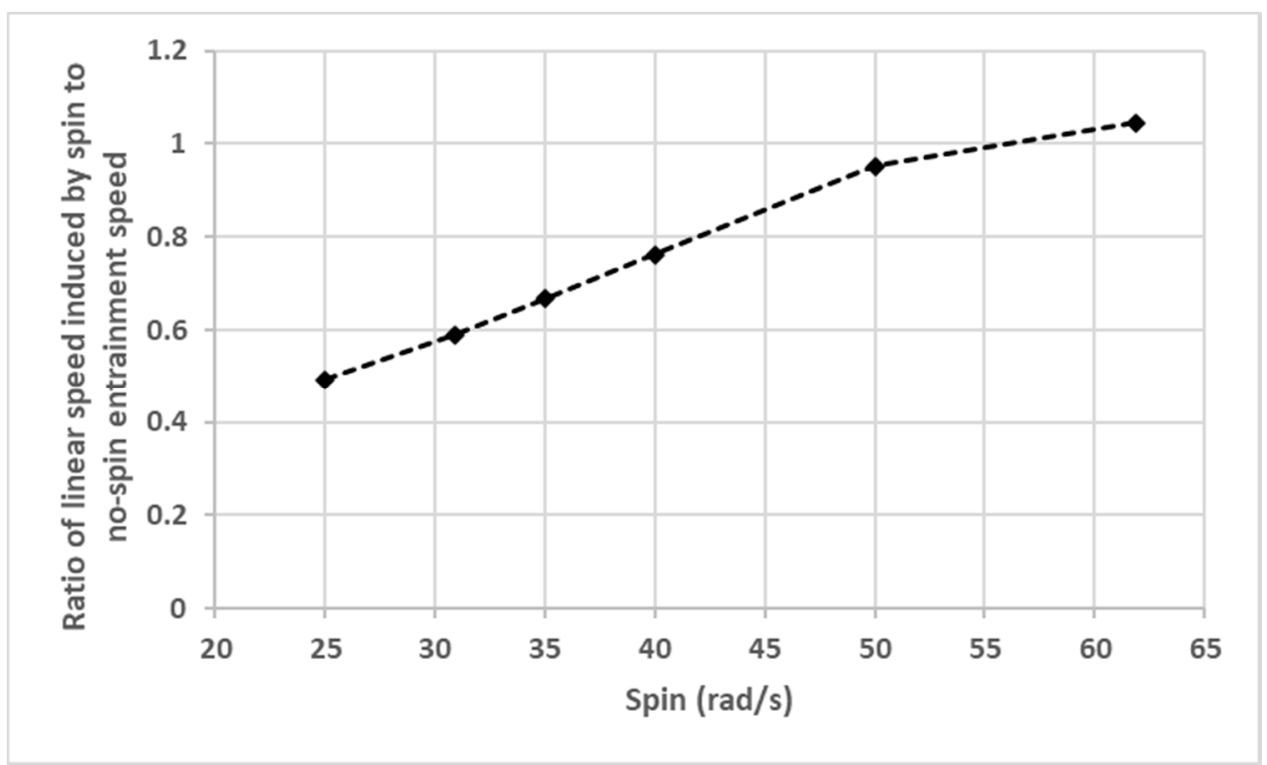

Figure 16. Variation of the ratio of spin-induced linear speed $\left(r_{s} \omega\right)$ to no-spin entrainment speed at the location of minimum oil film thickness.

\section{Concluding Remarks}

The paper highlights diverse applications of the elastohydrodynamic regime of lubrication in many load bearing lubricated conjunctions. The paper presents a comprehensive methodology for studying a multitude of different EHL conjunctions under steady state, quasi-steady and transient conditions. 
The methodology is validated against momentous historical experimental measurements/observations and numerical predictions of other research workers, showing very good agreement. In particular, emphasis is placed on complex combined rolling/sliding, mutually converging and separating (squeeze film) and spinning and reciprocating kinematics of contact for the case of point contact isothermal EHL. In-depth explanations for transient lubricant film thickness formation and variation is provided by the expounded fundamental study. In particular, transient effects due to combined rolling, squeeze film motion and spin, not hitherto studied, have been presented in the paper. The results show the dominant effect of squeeze film motion, and the rather insignificant effect of spin motion in the presence of other sources of contact kinematics. Spin only significantly affects the film thickness in the absence of rolling and sliding motions as the main sources of lubricant entrainment into the contact.

Author Contributions: Conceptualization: all, methodology: all, software: G.S., validation: G.S., formal analysis: all, investigation: G.S., data curation: G.S., original drafting: G.S., writing: G.S., review and editing: R.R. and H.R., visualization: G.S., supervision: R.R. and H.R., project administration: R.R. and H.R. All authors have read and agreed to the published version of the manuscript.

Funding: The authors would like to express their gratitude to the Engineering and Physical Sciences Research Council (EPSRC) for the financial support of this research under the Centre for Doctoral Training for Embedded Intelligence (CDT-EI); grant reference: EP/L014998/1.

Conflicts of Interest: The authors declare no conflict of interest.

\section{Nomenclature}

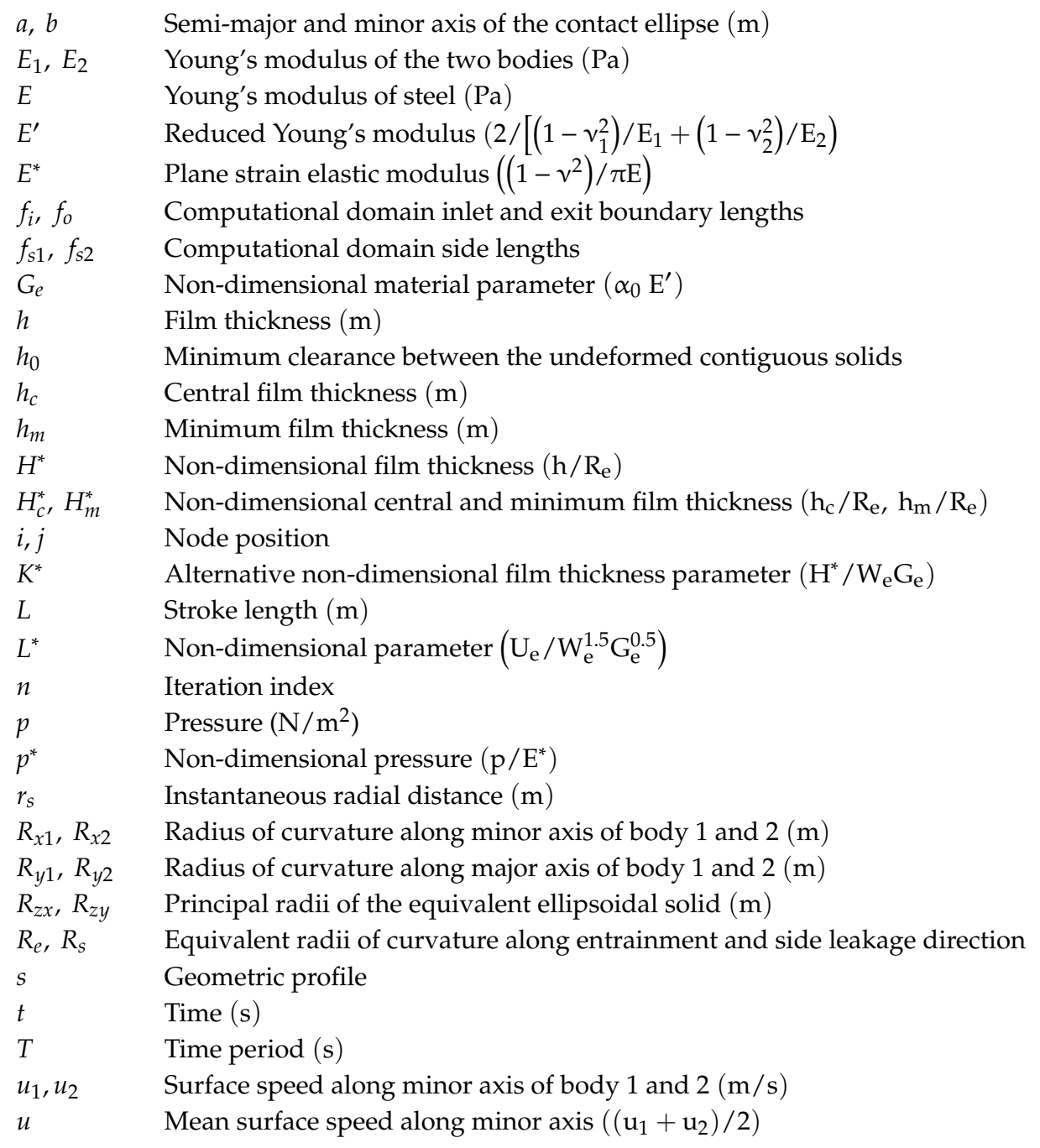




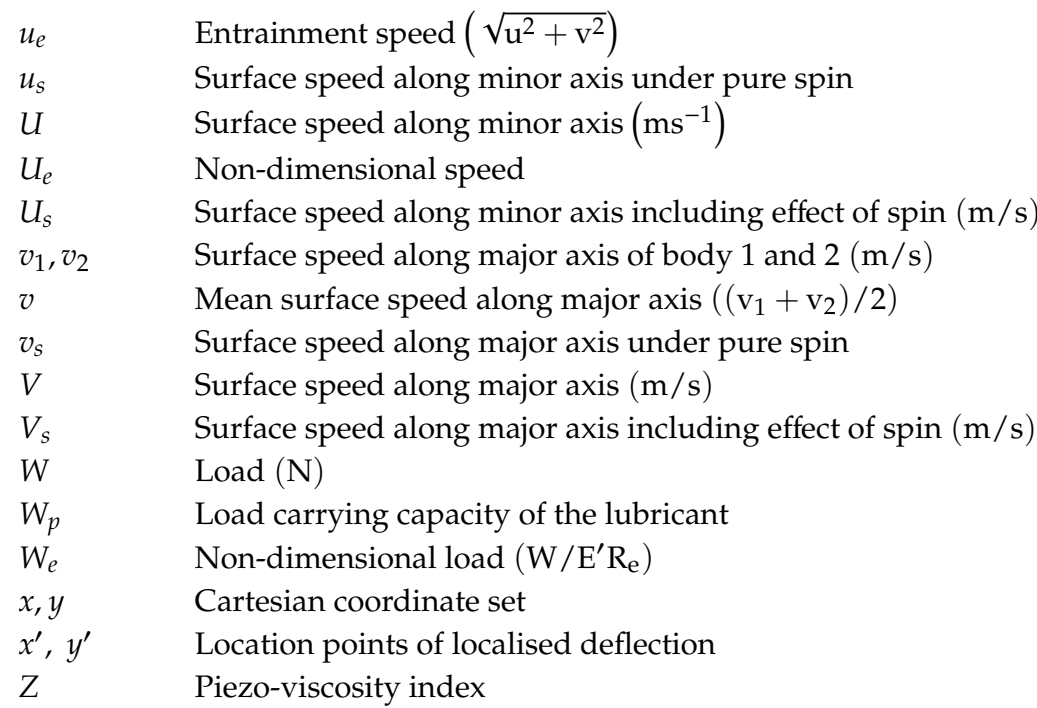

\section{Greek Symbols}

$\alpha_{0} \quad$ Piezo-viscosity coefficient at ambient temperature $(1 / \mathrm{Pa})$

$\delta \quad$ Local elastic deflection

$\varepsilon_{p}, \varepsilon_{w} \quad$ Convergence criterion for pressure and load

$\eta \quad$ Dynamic viscosity $\left(\mathrm{Ns} / \mathrm{m}^{2}\right)$

$\eta_{0} \quad$ Dynamic viscosity at ambient temperature and pressure $\left(\mathrm{Ns} / \mathrm{m}^{2}\right)$

$\theta \quad$ Angle entrained speed made with minor axis

$\eta_{r}, p_{r} \quad$ Roeland viscosity constant

$\rho \quad$ Density $\left(\frac{\mathrm{kg}}{\mathrm{m}^{3}}\right)$

$\rho_{0} \quad$ Density at ambient temperature and pressure $\left(\frac{\mathrm{kg}}{\mathrm{m}^{3}}\right)$

$v \quad$ Poisson ratio of steel

$v_{1}, v_{2} \quad$ Poisson's ratio of the two bodies

$\varsigma \quad$ Load relaxation factor

$\phi \quad$ Angle $r_{s}$ made with the minor axis

$\omega, \omega_{f} \quad$ Angular velocity ( $\left.\mathrm{rad} / \mathrm{s}\right)$

$\Omega \quad$ Under-relaxation factor

\section{Abbreviations}

EHL Elastohydrodynamic Lubrication

EIN Effective Influence Newton-Raphson

\section{References}

1. Cameron, A.; Gohar, R. Theoretical and experimental studies of the oil film in lubricated point contact. Proc. R. Soc. Ser. A 1966, 291, 520-536.

2. Dowson, D.; Higginson, G.R. Elastohydrodynamic Lubrication, SI ed.; Pergamon Press: Oxford, UK, 1977.

3. Hamrock, B.J.; Dowson, D. Isothermal elastohydrodynamic lubrication of point contacts: Part III-Fully flooded results. J. Tribol. 1977, 99, 264-275. [CrossRef]

4. Ehret, P.; Dowson, D.; Taylor, C.M.; Wang, D. Analysis of isothermal elastohydrodynamic point contacts lubricated by Newtonian fluids using multigrid methods. Proc. IMechE Part C J. Mech. Eng. Sci. 1997, 211, 493-508. [CrossRef]

5. Jalali-Vahid, D.; Rahnejat, H.; Gohar, R.; Jin, Z.M. Comparison between experiments and numerical solutions for isothermal elastohydrodynamic point contacts. J. Phys. D Appl. Phys. 1998, 31, 2725. [CrossRef] 
6. Venner, C.H.; Lubrecht, A.A. Multigrid techniques: A fast and efficient method for the numerical simulation of elastohydrodynamically lubricated point contact problems. Proc. IMechE Part J J. Eng. Tribol. 2000, 214, 43-62. [CrossRef]

7. Gohar, R.; Rahnejat, H. Fundamentals of Tribology; Imperial College Press: London, UK, 2008.

8. Sadeghi, F. Elastohydrodynamic lubrication. In Tribology and Dynamics of Engine and Powertrain; Woodhead Publishing: Cambridge, UK, 2010; pp. 171e-226e.

9. Dowson, D.; Higginson, G.R. A numerical solution to the elasto-hydrodynamic problem. J. Mech. Eng. Sci. 1959, 1, 6-15. [CrossRef]

10. Mostofi, A.; Gohar, R. Elastohydrodynamic lubrication of finite line contacts. J. Lubrication Technol. 1983, 105, 598-604. [CrossRef]

11. Kushwaha, M.; Rahnejat, H.; Gohar, R. Aligned and misaligned contacts of rollers to races in elastohydrodynamic finite line conjunctions. Proc. IMechE Part C J. Mech. Eng. Sci. 2002, 216, 1051-1070. [CrossRef]

12. Kushwaha, M.; Rahnejat, H. Transient concentrated finite line roller-to-race contact under combined entraining, tilting and squeeze film motions. J. Phys. D Appl. Phys. 2004, 37, 2018. [CrossRef]

13. Liu, X.; Yang, P. Numerical analysis of the oil-supply condition in isothermal elastohydrodynamic lubrication of finite line contacts. Tribol. Lett. 2010, 38, 115-124. [CrossRef]

14. Alakhramsing, S.S.; de Rooij, M.B.; Schipper, D.J.; van Drogen, M. Elastohydrodynamic lubrication of coated finite line contacts. Proc. IMechE Part J J. Eng. Tribol. 2018, 232, 1077-1092. [CrossRef]

15. Dowson, D.; Higginson, G.R.; Whitaker, A.V. Elasto-hydrodynamic lubrication: A survey of isothermal solutions. J. Mech. Eng. Sci. 1962, 4, 121-126. [CrossRef]

16. Larsson, R. Transient non-Newtonian elastohydrodynamic lubrication analysis of an involute spur gear. Wear 1997, 207, 67-73. [CrossRef]

17. Li, S.; Kahraman, A. Prediction of spur gear mechanical power losses using a transient elastohydrodynamic lubrication model. Tribol. Trans. 2010, 53, 554-563. [CrossRef]

18. Li, S.; Kahraman, A. Influence of dynamic behaviour on elastohydrodynamic lubrication of spur gears. Proc. IMechE Part J J. Eng. Tribol. 2011, 225, 740-753. [CrossRef]

19. Zhou, C.; Xiao, Z.; Chen, S.; Han, X. Normal and tangential oil film stiffness of modified spur gear with non-Newtonian elastohydrodynamic lubrication. Tribol. Int. 2017, 109, 319-327. [CrossRef]

20. Sivayogan, G.; Rahmani, R.; Rahnejat, H. Lubricated loaded tooth contact analysis and non-Newtonian thermoelastohydrodynamics of high-performance spur gear transmission systems. Lubricants 2020, 8, 20. [CrossRef]

21. De la Cruz, M.; Chong, W.W.F.; Teodorescu, M.; Theodossiades, S.; Rahnejat, H. Transient mixed thermo-elastohydrodynamic lubrication in multi-speed transmissions. Tribol. Int. 2012, 49, 17-29. [CrossRef]

22. Evans, H.P.; Snidle, R.W.; Sharif, K.J.; Shaw, B.A.; Zhang, J. Analysis of micro-elastohydrodynamic lubrication and prediction of surface fatigue damage in micropitting tests on helical gears. J. Tribol. 2013, 135, 011501. [CrossRef]

23. Jamali, H.U.; Sharif, K.J.; Evans, H.P.; Snidle, R.W. The transient effects of profile modification on elastohydrodynamic oil films in helical gears. Tribol. Trans. 2015, 58, 119-130. [CrossRef]

24. Simon, V.V. Optimal tooth modifications in face-hobbed spiral bevel gears to reduce the influence of misalignments on elastohydrodynamic lubrication. J. Mech. Des. 2014, 136, 071007. [CrossRef]

25. Rahnejat, H.; Rahmani, R.; Mohammadpour, M.; Johns-Rahnejat, P.M. Tribology of power train systems. In ASM Handbook; Friction, Lubrication, and Wear Technology; George, E., Ed.; ASM International: Novelty, OH, USA, 2017; Volume 18, pp. 916-934. (In Totten)

26. Bobach, L.; Beilicke, R.; Bartel, D. Transient thermal elastohydrodynamic simulation of a spiral bevel gear pair with an octoidal tooth profile under mixed friction conditions. Tribol. Int. 2020, 143, 106020. [CrossRef]

27. Xu, H.; Kahraman, A. Prediction of friction-related power losses of hypoid gear pairs. Proc. IMechE Part K J. Multi-Body Dyn. 2007, 221, 387-400. [CrossRef]

28. Simon, V.V. Improvements in the mixed elastohydrodynamic lubrication and in the efficiency of hypoid gears. Proc. IMechE Part J J. Eng. Tribol. 2019. [CrossRef]

29. Paouris, L.; Rahmani, R.; Theodossiades, S.; Rahnejat, H.; Hunt, G.; Barton, W. An analytical approach for prediction of elastohydrodynamic friction with inlet shear heating and starvation. Tribol. Lett. 2016, 64, 10. [CrossRef] 
30. Mohammadpour, M.; Theodossiades, S.; Rahnejat, H.; Dowson, D. Non-Newtonian mixed thermo-elastohydrodynamics of hypoid gear pairs. Proc. IMechE Part J J. Eng. Tribol. 2018, 232, 1105-1125. [CrossRef]

31. Chittenden, R.J.; Dowson, D.; Dunn, J.F.; Taylor, C.M. A theoretical analysis of the isothermal elastohydrodynamic lubrication of concentrated contacts, I. Direction of lubricant entrainment coincident with the major axis of the Hertzian contact ellipse. Proc. R. Soc. A 1985, 397, 245-269.

32. Evans, H.P.; Snidle, R.W. Wildhaber-Novikov circular arc gears: Elastohydrodynamics. J. Tribol. 1993, 115, 487-492. [CrossRef]

33. Omasta, M.; Křupka, I.; Hartl, M. Effect of surface velocity directions on elastohydrodynamic film shape. Tribol. Trans. 2013, 56, 301-309. [CrossRef]

34. Snidle, R.W.; Evans, H.P. Elastohydrodynamic Lubrication of Conformal Gears. In Advances in Gear Design and Manufacture; CRC Press: Boca Raton, FL, USA, 2019; pp. 151-164.

35. Dowson, D.; Taylor, C.M.; Zhu, G. A transient elastohydrodynamic lubrication analysis of a cam and follower. J. Phys. D Appl. Phys. 1992, 25, A313. [CrossRef]

36. Dowson, D.; Taylor, C. Dynamics and lubrication with particular reference to the internal combustion engine. In Multi-Body Dynamics: Monitoring and Simulation Techniques; Wiley: Hoboken, NJ, USA, 1997; p. 3.

37. Kushwaha, M.; Rahnejat, H. Transient elastohydrodynamic lubrication of finite line conjunction of cam to follower concentrated contact. J. Phys. D Appl. Phys. 2002, 35, 2872. [CrossRef]

38. Messe, S.; Lubrecht, A.A. Transient elastohydrodynamic analysis of an overhead cam/tappet contact. Proc. IMechE Part J J. Eng. Tribol. 2000, 214, 415-425. [CrossRef]

39. Chong, W.W.F.; Teodorescu, M.; Rahnejat, H. Mixed thermo-elastohydrodynamic cam-tappet power loss in low-speed emission cycles. Int. J. Engine Res. 2014, 15, 153-164. [CrossRef]

40. Turturro, A.; Rahmani, R.; Rahnejat, H.; Delprete, C.; Magro, L. Assessment of friction for cam-roller follower valve train system subjected to mixed non-Newtonian regime of lubrication. In Proceedings of the ASME 2012 Internal Combustion Engine Division Spring Technical Conference (ASME), Turin, Italy, 6-9 May 2012; pp. 917-923.

41. Torabi, A.; Akbarzadeh, S.; Salimpour, M. Comparison of tribological performance of roller follower and flat follower under mixed elastohydrodynamic lubrication regime. Proc. IMechE Part J J. Eng. Tribol. 2017, 231, 986-996. [CrossRef]

42. Alakhramsing, S.S.; de Rooij, M.B.; Schipper, D.J.; van Drogen, M. A full numerical solution to the coupled cam-roller and roller-pin contact in heavily loaded cam-roller follower mechanisms. Proc. IMechE Part J J. Eng. Tribol. 2018, 232, 1273-1284. [CrossRef]

43. Dowson, D.; Jin, Z.M. Metal-on-metal hip joint tribology. Proc. IMechE Part H J. Eng. Med. 2006, 220, 107-118. [CrossRef]

44. Dowson, D. Bio-tribology. Faraday Discuss. 2012, 156, 9-30. [CrossRef]

45. Jin, Z.M.; Dowson, D. Elastohydrodynamic lubrication in biological systems. Proc. IMechE Part J J. Eng. Tribol. 2005, 219, 367-380. [CrossRef]

46. Dowson, D. Developments in lubrication-the thinning film. J. Phys. D Appl. Phys. 1992, 25, A334. [CrossRef]

47. Grubin, A.N. Contact stresses in toothed gears and worm gears. In Book 30 CSRI for Technology and Mechanical Engineering; DSRI Trans.: Moscow, Russia, 1949; p. 337.

48. Vahid, D.J.; Rahnejat, H.; Jin, Z.M.; Downson, D. Transient analysis of isothermal elastohydrodynamic circular point contacts. Proc. IMechE Part C J. Mech. Eng. Sci. 2001, 215, 1159-1172. [CrossRef]

49. Ren, N.; Zhu, D.; Wen, S.Z. Experimental method for quantitative analysis of transient EHL. Tribol. Int. 1991, 24, 225-230. [CrossRef]

50. Wang, J.; Hashimoto, T.; Nishikawa, H.; Kaneta, M. Pure rolling elastohydrodynamic lubrication of short stroke reciprocating motion. Tribol. Int. 2005, 38, 1013-1021. [CrossRef]

51. Al-Samieh, M.F.; Rahnejat, H. Physics of lubricated impact of a sphere on a plate in a narrow continuum to gaps of molecular dimensions. J. Phys. D Appl. Phys. 2002, 35, 2311. [CrossRef]

52. Safa, M.M.A.; Gohar, R. Pressure distribution under a ball impacting a thin lubricant layer. J. Tribol. 1986, 108, 372-376. [CrossRef]

53. Dowson, D.; Wang, D. An analysis of the normal bouncing of a solid elastic ball on an oily plate. Wear 1994, 179, 29-37. [CrossRef] 
54. Wang, J.; Yang, P.; Lubrecht, A.A.; Kaneta, M. Numerical investigation of thermal EHL in elliptical contact under impact motion. Proc. IMechE Part J J. Eng. Tribol. 2015, 229, 1125-1131. [CrossRef]

55. Fryza, J.; Sperka, P.; Kaneta, M.; Krupka, I.; Hartl, M. Effects of lubricant rheology and impact speed on EHL film thickness at pure squeeze action. Tribol. Int. 2017, 106, 1-9. [CrossRef]

56. Thorp, N.; Gohar, R. Oil film thickness and shape for a ball sliding in a grooved raceway. J. Tribol. 1972, 94, 199-208. [CrossRef]

57. Thorp, N. Oil Film Thickness and Friction in Elliptical Contacts. Ph.D. Thesis, University of London, London, UK, 1972.

58. Jalali-Vahid, D.; Gohar, R.; Rahnejat, H.; Jin, Z.M. Prediction of oil-film thickness and shape in elliptical point contacts under combined rolling and sliding motion. Proc. IMechE Part J J. Eng. Tribol. 2000, 214, 427-437. [CrossRef]

59. Mohammadpour, M.; Theodossiades, S.; Rahnejat, H. Elastohydrodynamic lubrication of hypoid gear pairs at high loads. Proc. IMechE Part J J. Eng. Tribol. 2012, 226, 183-198. [CrossRef]

60. Mohammadpour, M.; Theodossiades, S.; Rahnejat, H. Transient mixed non-Newtonian thermo-elastohydrodynamics of vehicle differential hypoid gears with starved partial counter-flow inlet boundary. Proc. IMechE Part J J. Eng. Tribol. 2014, 228, 1159-1173. [CrossRef]

61. Mostofi, A.; Gohar, R. Oil film thickness and pressure distribution in elastohydrodynamic point contacts. Proc. IMechE Part C J. Mech. Eng. Sci. 1982, 24, 173-182. [CrossRef]

62. Li, X.M.; Guo, F.; Fan, B.; Yang, P. Influence of spinning on the rolling EHL films. Tribol. Int. 2010, 43, 2020-2028. [CrossRef]

63. Johnson, K.L. Contact Mechanics; Cambridge University Press: Cambridge, UK, 1985.

64. Roelands, C.J.A. Correlational Aspects of the Viscosity-Temperature-Pressure Relationship of Lubricating Oils. Ph.D. Thesis, Delft University of Technology, Delft, The Netherlands, 1966.

65. Bair, S.; Kottke, P. Pressure-viscosity relationships for elastohydrodynamics. Tribol. Trans. 2003, 46, $289-295$. [CrossRef]

66. Bair, S.S.; Andersson, O.; Qureshi, F.S.; Schirru, M.M. New EHL modeling data for the reference liquids squalane and squalane plus polyisoprene. Tribol. Trans. 2018, 61, 247-255. [CrossRef]

67. Liu, Y.; Wang, Q.J.; Bair, S.; Vergne, P. A quantitative solution for the full shear-thinning EHL point contact problem including traction. Tribol. Lett. 2007, 28, 171-181. [CrossRef]

68. Paouris, L.I. Thermo-Elastohydrodynamics of Hypoid Gears with Formulated Lubricants. Ph.D. Thesis, Loughborough University, Loughbrough, UK, 2016.

69. Havriliak, S.; Negami, S. A complex plane representation of dielectric and mechanical relaxation processes in some polymers. Polymer 1967, 8, 161-210. [CrossRef]

70. Paouris, L.; Rahmani, R.; Theodossiades, S.; Rahnejat, H.; Hunt, G.; Barton, W. Inefficiency predictions in a hypoid gear pair through tribodynamics analysis. Tribol. Int. 2018, 119, 631-644. [CrossRef]

71. Hamrock, B.J.; Dowson, D. Isothermal elastohydrodynamic lubrication of point contacts: Part 1-Theoretical formulation. J. Lubr. Technol. 1976, 98, 223-228. [CrossRef]

72. Paul, G.R.; Cameron, A. An absolute high-pressure microviscometer based on refractive index. Proc. R. Soc. Ser. A 1972, 331, 171-184.

(C) 2020 by the authors. Licensee MDPI, Basel, Switzerland. This article is an open access article distributed under the terms and conditions of the Creative Commons Attribution (CC BY) license (http://creativecommons.org/licenses/by/4.0/). 